\title{
Seasonal and diurnal trends in concentrations and fluxes of volatile organic compounds in central London
}

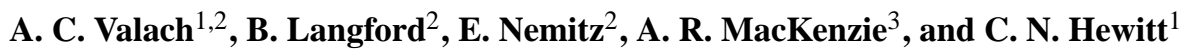 \\ ${ }^{1}$ Lancaster Environment Centre, Lancaster University, Lancaster, LA1 4YQ, UK \\ ${ }^{2}$ Centre for Ecology \& Hydrology, Bush Estate, Penicuik, Midlothian, EH26 0QB, UK \\ ${ }^{3}$ School of Geography, Earth and Environmental Sciences, University of Birmingham, \\ Edgbaston, Birmingham, B15 2TT, UK
}

Correspondence to: C. N. Hewitt (n.hewitt@lancaster.ac.uk)

Received: 6 February 2015 - Published in Atmos. Chem. Phys. Discuss.: 6 March 2015

Revised: 26 June 2015 - Accepted: 30 June 2015 - Published: 16 July 2015

\begin{abstract}
Concentrations and fluxes of seven volatile organic compounds (VOCs) were measured between August and December 2012 at a rooftop site in central London as part of the ClearfLo project (Clean Air for London). VOC concentrations were quantified using a proton transfer reaction mass spectrometer (PTR-MS) and fluxes were calculated using a virtual disjunct eddy covariance technique. The median VOC fluxes, including aromatics, oxygenated compounds and isoprene, ranged from 0.07 to $0.33 \mathrm{mg} \mathrm{m}^{-2} \mathrm{~h}^{-1}$. Median mixing ratios were $7.3 \mathrm{ppb}$ for methanol and $<1 \mathrm{ppb}$ for the other compounds. Strong relationships were observed between the fluxes and concentrations of some VOCs with traffic density and between the fluxes and concentrations of isoprene and oxygenated compounds with photosynthetically active radiation (PAR) and temperature. An estimated 50$90 \%$ of the fluxes of aromatic VOCs were attributable to traffic activity, which showed little seasonal variation, suggesting that boundary layer effects or possibly advected pollution may be the primary causes of increased concentrations of aromatics in winter. Isoprene, methanol and acetaldehyde fluxes and concentrations in August and September showed high correlations with PAR and temperature, when fluxes and concentrations were largest suggesting that biogenic sources contributed to their fluxes. Modelled biogenic isoprene fluxes from urban vegetation using the Guenther et al. (1995) algorithm agreed well with measured fluxes in August and September. Comparisons of estimated annual benzene emissions from both the London and the National Atmospheric Emissions Inventories agreed well with measured benzene
\end{abstract}

fluxes. Flux footprint analysis indicated emission sources were localised and that boundary layer dynamics and source strengths were responsible for temporal and spatial VOC flux and concentration variability during the measurement period.

\section{Introduction}

Currently over $50 \%$ of the global population lives in urban areas, and with increasing migration to urban centres, air quality remains a high public health priority. In the European Union, including in the UK, volatile organic compound (VOC) emissions are subject to control under the European Commission Directive 2008/50/EC and emission reducing technologies have been implemented, yet urban air pollution continues to be a concern. VOCs from both anthropogenic and biogenic sources impact urban air quality and climate through their contribution to tropospheric ozone and aerosol particle formation. Some VOCs, including benzene and 1,3butadiene are also carcinogens that can directly affect human health (Kim et al., 2001). Most VOCs in urban areas are assumed to come from fuel combustion or evaporative emissions (Kansal, 2009; Srivastava et al., 2005). However, in summer urban vegetation may act as an additional source of VOCs such as methanol, isoprene and monoterpenes, even in cities with a temperate climate and little green space such as London or Manchester (Langford et al., 2009, 2010b). 
Emission inventories such as the London Atmospheric Emissions Inventory (LAEI, http://www. cleanerairforlondon.org.uk/londons-air/air-quality-data/ london-emissions-laei/road-traffic-emissions) and the National Atmospheric Emissions Inventory (NAEI, http://naei.defra.gov.uk/data/) use a "bottom-up" approach based on activity data and emission factors to estimate emission rates from pollutant sources. Micrometeorologically based eddy covariance techniques allow a "top-down" approach to quantify fluxes and these measurements can be compared with modelled emission inventory estimates. Such comparisons are essential as "bottom-up" emission inventories may inadvertently not include specific pollutant sources or may use unrepresentative emission factors or activity profiles. "Top-down" approaches using Earth observation data from satellites are also available for a few chemicals (Lamsal et al., 2011) but not for primary VOCs. There have been few studies on VOC fluxes in urban areas, and these have been limited in spatial and temporal extent (Langford et al., 2009, 2010b; Park et al., 2010, 2011; Velasco et al., 2005, 2009). Due to the high technical demands of VOC flux measurements, it is difficult to increase spatial coverage or to make measurements for long periods of time. Making further measurements of this kind is therefore a high priority in studies of air quality.

In this study we present flux and concentration measurements of seven selected volatile organic compounds made over 5 months in central London using the virtual disjunct eddy covariance method. The aims of this study were to (i) quantify VOC fluxes above an urban canopy using proton transfer reaction mass spectrometry and virtual disjunct eddy covariance; (ii) investigate seasonal, diurnal and spatial differences in VOC fluxes and concentrations; (iii) examine possible major source contributions of speciated VOCs in central London; and (iv) compare measured fluxes with those estimated by both the LAEI and the NAEI.

These observations were made as part of the ClearfLo (Clean air for London) project, which provided integrated short-term and long-term measurements of meteorology, gas phase and particulate pollutants over London and surrounding areas during 2011 and 2012 (Bohnenstengel et al., 2015).

\section{Methods}

\subsection{Measurement site}

Micrometeorological flux measurements were made during the period 7 August-19 December 2012 from a flux tower located on the roof of a building belonging to King's College, University of London $\left(51.511667^{\circ} \mathrm{N}, 0.116667^{\circ} \mathrm{W}\right.$; ground altitude $30 \mathrm{~m}$ a.s.1.), on the Strand in central London. Although the site is within the London Congestion Charge Zone (an area encompassing central London requiring road tolls to be paid and hence an area with reduced traffic density), surrounding roads supported a medium to high traffic volume (annual average of 50 000-80000 vehicles per day; Department for Transport, 2014) with the River Thames situated $200 \mathrm{~m}$ to the south. This site is classified as a local climate zone class 2 compact midrise according to Stewart and Oke (2012) (i.e. dense mix of midrise buildings; 3-9 stories; few or no trees; land cover mostly paved; stone, brick, tile and concrete construction materials). Land cover types (in \%) were calculated based on the Ordnance Survey map for the surrounding $9 \mathrm{~km}^{2}$ area (Fig. 1) encompassing the site and are roads $(37 \%)$, buildings $(31 \%)$, other paved areas $(14 \%)$, unpaved/vegetation (11\%) and water bodies (7\%).

The sampling inlet and sonic anemometer were mounted on a triangular mast (Aluma T45-H) at approx. $60.9 \mathrm{~m}(2.3$ times mean building height, $z_{\mathrm{H}}$ ) above ground level. The mean building height was around $25 \mathrm{~m}$ and the mast was located on an elevated area in the centre of the roof. A street canyon was located to the NW and an enclosed parking area to the SE, but generally surrounding buildings were of equal height. The sampling point (which we call KCL) is located $37 \mathrm{~m}$ west of a sampling point (KSS) that has been used for long-term energy and $\mathrm{CO}_{2}$ flux measurements (Kotthaus and Grimmond, 2012). Although the site is not optimal for micrometeorological flux measurements due to the heterogeneity of the urban canopy, its suitability has been assessed in detail by Kotthaus and Grimmond (2014a, b). This study describes in detail the measurement area and investigates the influence of source area characteristics on long-term radiation and turbulent heat fluxes for the KSS site. They conclude that the site can yield reasonable data on surface-to-atmosphere fluxes.

The weather in 2012 was somewhat cooler than the 1981 to 2010 long-term mean for London during summer and autumn, with several cold fronts bringing up to twice as much precipitation and associated winds as average, suppressing pollution levels. However, during the period of the Olympic and Paralympic games (27 July-12 August and 29 August9 September 2012) the weather was hot and dry, causing sustained pollution peaks. Winter 2012/2013 was generally warmer and drier in London than the 1981-2010 mean (Met Office, 2013).

\subsection{Instrumentation and data acquisition}

The CSAT3 sonic anemometer (Campbell Scientific Inc., Utah, USA) and inlet were faced toward the predominant wind direction (SW) to minimise flow distortion. Data from the sonic anemometer were logged at a frequency of $10 \mathrm{~Hz}$ and flux measurements were calculated using 25 min averaging periods. The rotation angle theta $(\theta)$, used to correct measurements of the vertical wind velocity for minor misalignment of the sonic anemometer, showed no significant disturbance of the turbulence from interactions with the building when plotted against wind direction. Data were recorded in UTC (universal time coordinated), which is $1 \mathrm{~h}$ earlier than 


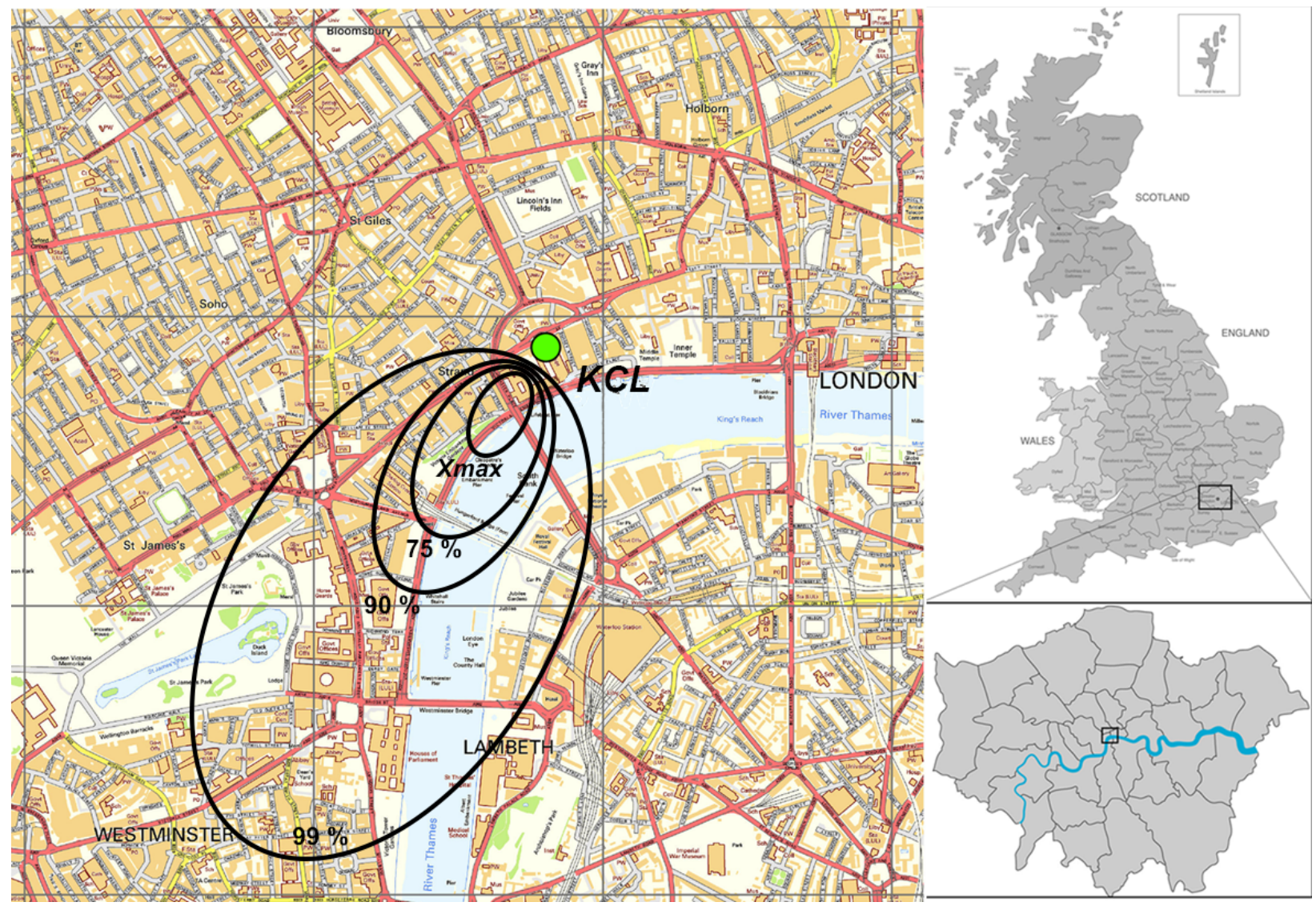

Figure 1. Map of central London overlaid with the Ordnance Survey grid including the measurement site (KCL) at King's College (green point) with references to the geography of Greater London and Great Britain. Outlines of the areas that contribute the maximum $\left(X_{\text {max }}\right)$ as well as 75,90 and $99 \%$ to the flux footprint using overall median meteorological values are shown as black contour lines with their respective labels laid out according to the median wind direction.

local time in summer and coincident with Greenwich mean time in winter. However, all analyses used local time.

VOC concentrations were measured using a highsensitivity proton transfer reaction (quadrupole) mass spectrometer (PTR-MS) (Ionicon Analytik GmbH, Innsbruck, Austria) with three Varian turbomolecular pumps (see for example de Gouw and Warneke, 2007; Hayward et al., 2002; Lindinger et al., 1998, for more detailed description of the instrument). Air was drawn through an inlet co-located with the sonic anemometer. Sample air was purged through a $\sim 30 \mathrm{~m}$ $\frac{1}{2}^{\prime \prime}$ OD $\left(\frac{3}{8}{ }^{\prime \prime}\right.$ ID) PTFE tube at a flow rate of $81 \mathrm{~L} \mathrm{~min}^{-1}$ to the PTR-MS, which was housed in a utility room below. The high flow rate ensured turbulent flow was maintained and signal attenuation minimised (Reynolds number, $R e=11177$ ). During the campaign, PTR-MS operating parameters were maintained at $1.95 \mathrm{mbar}, 510 \mathrm{~V}$ and $50^{\circ} \mathrm{C}$ for drift tube pressure, voltage and temperature respectively to achieve an $E / N$ ( $E$ is the electric field strength and $N$ is the buffer gas number density) ratio of $123 \mathrm{Td}\left(1 \mathrm{Td}=10^{-17} \mathrm{~V} \mathrm{~cm}^{2}\right)$. This field strength forms a compromise between reagent ion clustering and fragmentation suppression (Hewitt et al., 2003).
Further instrument parameters and meteorological conditions are summarised in Table 1. The inlet flow rate into the instrument was $0.25-0.3 \mathrm{~L} \mathrm{~min}^{-1}$.

The logging program was written in LabVIEW (National Instruments, Austin, Texas, USA) and operated the PTRMS in multiple ion detection (MID) and SCAN modes for VOC concentrations of nine selected masses and a range of the protonated mass spectrum $m / z$ 21-206 respectively. The sonic anemometer was not directly interfaced with the LabVIEW logging program, requiring the measurements to be synchronised during post-processing through the use of a cross-correlation function between the vertical wind velocity $w$ and the VOC ion counts $c$. A valve system controlled the measurement cycle, which consisted of $5 \mathrm{~min}$ zero air (ZA), $25 \mathrm{~min}$ MID followed by $5 \mathrm{~min}$ SCAN of sample air and $25 \mathrm{~min}$ MID mode. During the ZA cycle, air was pumped through a custom-made gas calibration unit fitted with a platinum catalyst heated to $200^{\circ} \mathrm{C}$ to provide instrument background values at ambient humidity. In MID mode the quadrupole scanned nine predetermined protonated masses with a dwell time of $0.5 \mathrm{~s}$, 
Table 1. Summary of instrument operating parameters and average meteorological conditions during the measurements in central London, August-December 2012.

\begin{tabular}{|c|c|c|}
\hline Parameter & Unit & Mean (range) \\
\hline Normalised sensitivity $\left(S_{\mathrm{N}}\right)^{\text {a }}$ & ncps ppb ${ }^{-1}$ & $\begin{array}{l}11.5(\mathrm{~m} / \mathrm{z} 33), 13.3(\mathrm{~m} / \mathrm{z} 45), 10(\mathrm{~m} / \mathrm{z} 59), 4(\mathrm{~m} / \mathrm{z} 69), \\
3.6(\mathrm{~m} / \mathrm{z} 79), 2.5(\mathrm{~m} / \mathrm{z} 93), 1.5(\mathrm{~m} / \mathrm{z} 107)\end{array}$ \\
\hline Primary ion $(m / z 19)$ & Cps & $8.31 \times 10^{6}\left(6.14 \times 10^{6}-1.15 \times 10^{7}\right)$ \\
\hline Water cluster $(m / z, 37)$ & $\begin{array}{l}\text { Cps } \\
0 \text { of } m / z 19\end{array}$ & $1.92 \times 10^{5}\left(9.15 \times 10^{4}-3.86 \times 10^{5}\right)$ \\
\hline $\mathrm{O}_{2}^{+}$ & $\%$ of $m / z 19$ & $<1.45(1.11-2.01)$ \\
\hline Temperature $^{\mathrm{b}}$ & ${ }^{\circ} \mathrm{C}$ & $14.0(-1.81-30.39)$ \\
\hline Relative humidity & $\%$ & $76(50-97)$ \\
\hline Pressure & mbar & $1004.27(968.71-1023.27)$ \\
\hline Wind speed ${ }^{\mathrm{b}}$ & $\mathrm{m} \mathrm{s}^{-1}$ & $3.35(0.12-14.96)$ \\
\hline Friction velocity $\left(u_{*}\right)^{\mathrm{b}}$ & $\mathrm{ms}^{-1}$ & $0.5(0.01-1.50)$ \\
\hline SD of vertical wind speed $\left(\sigma_{\mathrm{W}}\right)^{\mathrm{b}}$ & $\mathrm{ms}^{-1}$ & $0.65(0.15-1.62)$ \\
\hline
\end{tabular}

${ }^{\mathrm{a}} S_{\mathrm{N}}$ : normalised sensitivity as calculated using Taipale et al. (2008). ${ }^{\mathrm{b}}$ Derived from measurements from the CSAT3 sonic anemometer (Campbell Scientific).

to which each of the following compounds were ascribed: $m / z 21$ (indirectly quantified $m / z 19$ primary ion count via $\left[\mathrm{H}_{3}^{18} \mathrm{O}^{+}\right]$), $m / z 33$ (methanol), $m / z 39$ (indirectly quantified $m / z 37$ first cluster $\left[\mathrm{H}_{3} \mathrm{O}^{+} \mathrm{H}_{2} \mathrm{O}^{+}\right]$), $m / z 42$ (acetonitrile, results not shown), $m / z 45$ (acetaldehyde), $m / z 59$ (acetone/propanal), $m / z 69$ (isoprene/furan), $m / z 79$ (benzene), $\mathrm{m} / \mathrm{z} 93$ (toluene), $\mathrm{m} / \mathrm{z} 107\left(\mathrm{C}_{2}\right.$-benzenes) and $\mathrm{m} / \mathrm{z} 121$ $\left(\mathrm{C}_{3}\right.$-benzenes, results not shown). The total cycle time was $5.5 \mathrm{~s}$. Secondary electron multiplier voltage, as well as $\mathrm{O}_{2}^{+}$ $(m / z$ 32) and photon "dark counts" $(m / z, 25)$ signals, were monitored weekly.

The PTR-MS cannot distinguish between different compounds with the same integer mass; therefore, isobaric interference can occur. For example, $m / z 107$ may result from several contributing $\mathrm{C}_{8}$ aromatics: ethyl benzene, $(m+p)$ xylene, $o$-xylene and some benzaldehyde (Warneke et al., 2003). Further interferences at measured $\mathrm{m} / \mathrm{z}$ from additional compounds and fragmentation for this instrument in an urban environment are discussed in Valach et al. (2014). Although the $\mathrm{O}_{2}^{+}$and water cluster ions were kept $<2 \%$ of the primary ion, interferences from ${ }^{17} \mathrm{O}^{+}$isotopes at $m / z 33$ were taken into account.

Single point calibrations were performed on-site once a month using a certified multiple component VOC gas standard (Ionimed, part of Ionicon Analytik GmbH, Austria), which was validated by cross-calibration with a second independent VOC standard (Apel Riemer Environmental Inc., CO, USA). Before and after the campaign, multistep calibrations were performed with both standards. Standards were diluted with catalytically converted zero air, since cylinder concentrations were approx. $1 \mathrm{ppm} \pm 5 \%$ uncertainty (Ionimed Analytik) and $0.5 \mathrm{ppm} \pm 10 \%$ (Apel Riemer). Error propagation resulted in a total calibration uncertainty of $<20 \%$. Measured normalised instrument sensitivities $\left(S_{\mathrm{N}}\right.$, Table 1$)$ based on Taipale et al. (2008) were used to convert nor- malised count rates (ncps) of protonated masses $\left(\mathrm{RH}^{+}\right)$to volume mixing ratios (Langford et al., 2010a). Only the $o$ xylene isomer was present in the Ionimed standard, which was used to determine instrument sensitivities for $m / z 107$, but sensitivities agreed well when compared with sensitivities for $p$-xylene present in the Apel Riemer standard. Any remaining humidity effects on calibrations were previously investigated for this instrument and were found to be within the overall calibration uncertainty (Valach et al., 2014). Detection limits of VOC concentrations (Table 2) were calculated according to Taipale et al. (2008).

\subsection{Flux calculations and quality assessment}

Fluxes were calculated according to Karl et al. (2002) and Langford et al. (2009, 2010b) using

$F=\frac{1}{n} \sum_{i=1}^{n} w^{\prime}\left(\frac{i-t_{\mathrm{lag}}}{\Delta_{\mathrm{tw}}}\right) \times c^{\prime}(i)$,

where $w^{\prime}$ and $c^{\prime}$ are the instantaneous fluctuations around the mean vertical wind $(w-\bar{w})$ and mean VOC concentration $(c-\bar{c}), n$ is the number of VOC concentration measurements per $25 \mathrm{~min}$ averaging period $(n=273), t_{\mathrm{lag}}$ is the lag time between the wind and PTR-MS measurement due to the transit through the sampling line and $\Delta_{\text {tw }}$ is the sampling interval of the vertical wind speed measurements of the sonic anemometer $(10 \mathrm{~Hz}=0.1 \mathrm{~s})$. Langford et al. (2015) recently demonstrated that the method used to determine the time lag becomes important where the signal-to-noise ratio of the analyser is poor, showing that methods that systematically search for a maximum in the cross-correlation function within a given window (MAX method) can bias the calculated fluxes towards more extreme (positive or negative) values. Their study recommends the use of a prescribed lag time determined either through the use of a monitored sample flow 
Table 2. Summary of 25 min VOC fluxes and mixing ratios above central London during August-December 2012.

\begin{tabular}{|c|c|c|c|c|c|c|c|}
\hline $\begin{array}{l}\text { Compound } \\
(m / z)\end{array}$ & $\begin{array}{l}\text { Methanol } \\
(m / z 33)\end{array}$ & $\begin{array}{l}\text { Acetaldehyde } \\
\qquad(m / z 45)\end{array}$ & $\begin{array}{r}\text { Acetone/propanal } \\
(m / z 59)\end{array}$ & $\begin{array}{r}\text { Isoprene/furan } \\
(m / z 69)\end{array}$ & $\begin{array}{l}\text { Benzene } \\
(m / z 79)\end{array}$ & $\begin{array}{l}\text { Toluene } \\
(m / z 93)\end{array}$ & $\begin{array}{r}\mathrm{C}_{2} \text {-benzenes } \\
(m / z, 107)\end{array}$ \\
\hline \multicolumn{8}{|c|}{ Fluxes $\left(\mathrm{mg} \mathrm{m}^{-2} h^{-1}\right)$} \\
\hline Lifetime $\left(\mathrm{OH}^{\mathrm{a}}\right)$ & $12 \mathrm{~d}$ & $8.8 \mathrm{~h}$ & $53 \mathrm{~d}$ & $1.4 \mathrm{~h}$ & $9.4 \mathrm{~d}$ & $1.9 \mathrm{~d}$ & $5.9 \mathrm{~h}$ \\
\hline$N$ & 2920 & 2811 & 2945 & 2119 & 1908 & 2315 & 2053 \\
\hline Min. & -2.91 & -0.28 & -1.74 & -0.35 & -0.64 & -2.31 & -3.27 \\
\hline First quartile & 0.12 & 0.06 & 0.10 & 0.02 & 0.002 & 0.08 & 0.04 \\
\hline Median & 0.27 & 0.14 & 0.22 & 0.09 & 0.07 & 0.30 & 0.33 \\
\hline Mean & 0.29 & 0.16 & 0.31 & 0.13 & 0.09 & 0.41 & 0.54 \\
\hline Third quartile & 0.42 & 0.23 & 0.40 & 0.20 & 0.18 & 0.64 & 0.91 \\
\hline Max. & 3.36 & 1.09 & 2.85 & 1.16 & 0.59 & 4.86 & 8.63 \\
\hline SD & 0.25 & 0.15 & 0.34 & 0.16 & 0.15 & 0.53 & 0.86 \\
\hline Skew & 0.86 & 1.27 & 2.08 & 1.18 & 0.32 & 1.75 & 2.33 \\
\hline Kurtosis & 20.37 & 2.85 & 7.57 & 2.81 & 0.76 & 8.04 & 14.48 \\
\hline \multicolumn{8}{|c|}{ Mixing ratios (ppb) } \\
\hline$N$ & 4834 & 4834 & 4834 & 4834 & 4834 & 4834 & 4834 \\
\hline Min. & 5.73 & $<\operatorname{LoD}(0.14)$ & $<\operatorname{LoD}(0.02)$ & $<\operatorname{LoD}(0.03)$ & $<\operatorname{LoD}(0.04)$ & $<\operatorname{LoD}(0.05)$ & $<\operatorname{LoD}(0.14)$ \\
\hline 1. quartile & 6.82 & 0.59 & $<\operatorname{LoD}(0.65)$ & $<\operatorname{LoD}(0.16)$ & $<\operatorname{LoD}(0.18)$ & $<\operatorname{LoD}(0.38)$ & $<\operatorname{LoD}(0.57)$ \\
\hline Median & 7.27 & 0.82 & 0.95 & $<\operatorname{LoD}(0.22)$ & $<\operatorname{LoD}(0.24)$ & $<\operatorname{LoD}(0.54)$ & 0.75 \\
\hline Mean & 7.53 & 0.94 & 1.10 & 0.25 & 0.29 & $<\operatorname{LoD}(0.65)$ & 0.87 \\
\hline 3. quartile & 7.90 & 1.13 & 1.36 & 0.30 & 0.34 & 0.77 & 1.03 \\
\hline Max. & 17.06 & 5.17 & 6.07 & 1.86 & 1.71 & 5.30 & 4.96 \\
\hline SD & 1.12 & 0.53 & 0.66 & 0.14 & 0.19 & 0.45 & 0.50 \\
\hline Skew & 2.21 & 2.14 & 1.65 & 1.97 & 2.80 & 3.07 & 2.79 \\
\hline Kurtosis & 7.22 & 7.83 & 4.06 & 7.27 & 12.37 & 15.89 & 12.99 \\
\hline $\operatorname{LoD}^{\mathrm{b}}$ & 0.96 & 0.45 & 0.66 & 0.25 & 0.28 & 0.66 & 0.71 \\
\hline
\end{tabular}

a Atmospheric lifetimes with regard to $\mathrm{OH}$ for a $12 \mathrm{~h}$ daytime average $\mathrm{OH}$ concentration of $2.0 \times 10^{6}$ molecules $\mathrm{cm}^{-3}$ (Atkinson, 2000).

${ }^{\mathrm{b}}$ LoD: limit of detection calculated using Taipale et al. (2008).

rate or by using the typical lag time derived by searching for a maximum. Here the prescribed lag times were determined by fitting a running mean to the time series of daytime lag times calculated using the MAX method for acetone, which had large fluxes and the clearest time lags. Prescribed lag times for all other compounds were set relative to that of acetone, accounting for the offset introduced by the sequential sampling of the PTR-MS.

Flux losses due to the attenuation of high and low frequency eddies were estimated for our measurement setup. High frequency flux attenuation was estimated to be on average $11 \%$ using the method of Horst (1997), and a correction was applied. Attenuation from low frequency fluctuations for a $25 \mathrm{~min}$ flux period was investigated by reanalysing the sensible heat fluxes for longer averaging periods of 60 , 90,120 and $150 \mathrm{~min}$. The coordinate rotation was applied to the joined files, which acted as a high pass filter to the three wind vectors, confirming that fluctuations of eddies with a longer time period than the averaging time did not contribute to the flux measurement (Moncrieff et al., 2004). The fluxes were compared to the $25 \mathrm{~min}$ average fluxes, which had the coordinate rotation applied before joining, again to ensure only turbulent fluctuations of $\leq 25 \mathrm{~min}$ contributed to the flux (Fig. A1 in the Supplement). Flux losses due to low frequency attenuation were estimated to be $<1.5 \%$ and, therefore, no corrections were deemed necessary. The error due to the disjunct sampling was estimated by comparing the sensible heat fluxes calculated from the continuous data series with those calculated from a disjunct data series using a set sampling interval of $5.5 \mathrm{~s}$. The continuous data were averaged to match the sampling frequency of the disjunct data (i.e. $2 \mathrm{~Hz}$ ). The difference between the eddy covariance and DEC sensible heat fluxes was minimal $(0.01 \%)$ and thus no additional corrections were applied.

Many of the $25 \mathrm{~min}$ resolved flux measurements were close to the limit of detection (LoD), based on 1 standard deviation using the method of Spirig et al. (2005), with an average fail rate of $82 \%$. Various techniques to statistically analyse or replace values below the LoD have been developed (Clarke, 1998). However, they often result in significant bias, either high or low depending on the value substituted, because values tend to be below the LoD when fluxes are indeed small (Helsel and Hirsch, 1992). In this study, our analysis focused on diurnally averaged flux profiles and we 
decided not to filter out individual flux values on the basis of being < LoD in order to avoid this bias. When averaging the 25 min flux data it is appropriate to also average the LoD which, as shown by Langford et al. (2015), decreases with the square root of the number of samples averaged $(N)$. Therefore, although the majority of the individual $25 \mathrm{~min}$ flux measurements were below the LoD, their diurnal average profiles may exceed the LoD for the average and thus still yield important data on the net exchange of VOCs above the city.

$\overline{\mathrm{LoD}}=\frac{1}{N} \sqrt{\sum_{i=1}^{N} \mathrm{LoD}^{2}}$.

The following describes the additionally applied filter criteria. $25 \mathrm{~min}$ flux values with a friction velocity $\left(u_{*}\right)<0.15 \mathrm{~m} \mathrm{~s}^{-1}$ were rejected $(3.4 \%$ of total data) due to insufficient turbulence. The stationarity test and data quality rating methods of Foken and Wichura (1996) and Velasco et al. (2005) were used, and $47 \%$ of the data files were rejected on this basis. The high number of files rejected in the stationarity test is to be expected for eddy covariance measurements over highly heterogeneous canopies, although horizontally averaged canopy morphology recovers some surface homogeneity. Furthermore, the low measurement height used can cause an increased sensitivity towards canopy roughness features resulting in non-stationarity. Since urban environments are inherently not ideal for micrometeorological flux measurements due to their heterogeneity, integral turbulence characteristics of this site were assessed by comparing the measured standard deviation of the vertical wind velocity $\left(\sigma_{\mathrm{w}}\right)$ normalised by $u_{*}$ to the parameters of a modelled ideal turbulence (Foken et al., 2004). Results showed that $99.6 \%$ of all the data was rated category six or better and $0.4 \%$ was rejected using the criteria of Foken et al. (2004). This large pass rate gives further confidence that the measurements were not unduly affected by wake turbulence generated from the structure of the building. Erroneous meteorological data $(2.6 \%$ of total) were removed around wind directions of $14-15^{\circ}$ due to minor turbulence interferences from the presence of other sensors on the mast. Depending on the compound, between 40 and $61 \%$ of flux data $(N=1934$ 2949 ) passed all of the above quality controls. Exactly $2014 \mathrm{~h}$ of concentration data ( $N=4834)$ was obtained. For consistency, regression coefficients $\left(R^{2}\right)$ were used throughout.

The traffic densities used for the analysis were obtained from a nearby site at Marylebone Road (approx. $3 \mathrm{~km}$ to the $\mathrm{NW}$ ) and consisted of hourly vehicle counts covering the period 7-22 August 2012. The major roads of the Strand and the Thames Embankment surrounding the measurement site support a comparable traffic volume with an annual average of 50000-80000 vehicles per day (Department for Transport, 2014) and diurnal patterns in traffic are likely to be similar across central London.

Photosynthetically active radiation (PAR) and $\mathrm{CO}_{2}$ measurements used in the analysis were part of the long-term micrometeorological measurements at the same site and covered the period from August to September for PAR and from August to December for $\mathrm{CO}_{2}$. Average diurnal profiles were calculated for the boundary layer mixing height, which was measured using three LiDARs located on rooftops within central London during an approx. 2-week period in summer and winter 2012 (Bohnenstengel et al., 2015).

\section{Flux footprint calculations}

Although there are no operational footprint models for urban environments that take the complex topography and spatial variability in building height and surface heat fluxes into account, the analytical footprint model of Kormann and Meixner (2001) has previously been applied in nonhomogeneous terrain (Helfter et al., 2011; Neftel et al., 2008). The Kormann-Meixner (KM) model determines the 2-D footprint density function explicitly from micrometeorological parameters, which are provided by the eddy covariance measurements, i.e. friction velocity $\left(u_{*}\right)$, measurement height $\left(z_{\mathrm{m}}\right)$, Obukhov length $(L)$, horizontal wind velocity at the measurement height $\left(u\left(z_{\mathrm{m}}\right)\right)$ and standard deviation of the lateral wind $\left(\sigma_{v}\right)$. The flux footprints were calculated for each 25 min flux period. Neftel et al. (2008) developed a Microsoft Excel-based tool that allows the footprint contributions (\%) of user-defined spatial elements to be mapped. In this case we used a total of nine $1 \mathrm{~km}^{2}$ grid squares to match the Ordnance Survey (OS) grid (Fig. 1), centred on the measurement site. This grid resolution was validated using a simple parameterisation model (Kljun et al., 2004) with average diurnal cycle parameters for $\sigma_{\mathrm{w}}, u_{*}$ and boundary layer height $\left(z_{i}\right)$ during the campaign, which calculated the distance of the maximum flux contribution $\left(X_{\max }\right)$ and the extent of the $90 \%$ flux footprint $\left(X_{90}\right)$.

The KM footprint calculation requires the MoninObukhov stability parameter $(\zeta)$ to be within the interval $[-3,3]$, where

$\zeta=\frac{z_{\mathrm{m}}-d}{L}$,

with $d\left(d=\frac{2}{3} z_{\mathrm{H}}=16.7 \mathrm{~m}\right)$ being the displacement height estimated as a fraction of the canopy height (Garrat, 1992). The footprint estimation for cases of extreme stability is of lower quality but still provides useful information. The vertical turbulent flux $F_{c}\left(0,0, z_{\mathrm{m}}\right)$ measured at the height $z_{\mathrm{m}}$ is related to the corresponding surface flux area $F_{c}(x, y, 0)$, which is upwind of the measurement point, such that

$$
\begin{aligned}
F_{c}\left(0,0, z_{\mathrm{m}}-d\right) & =\int_{\infty}^{-\infty} \int_{0}^{\infty} F_{c}\left(x, y, z_{\mathrm{m}}-d\right) \\
& \times \Phi\left(x, y, z_{\mathrm{m}}-d\right) \mathrm{d} x \mathrm{~d} y,
\end{aligned}
$$

where $z_{\mathrm{m}}$ is the measurement height and the $x$ axis is aligned with the mean horizontal wind direction. $\Phi\left(x, y, z_{\mathrm{m}}-d\right)$ is 

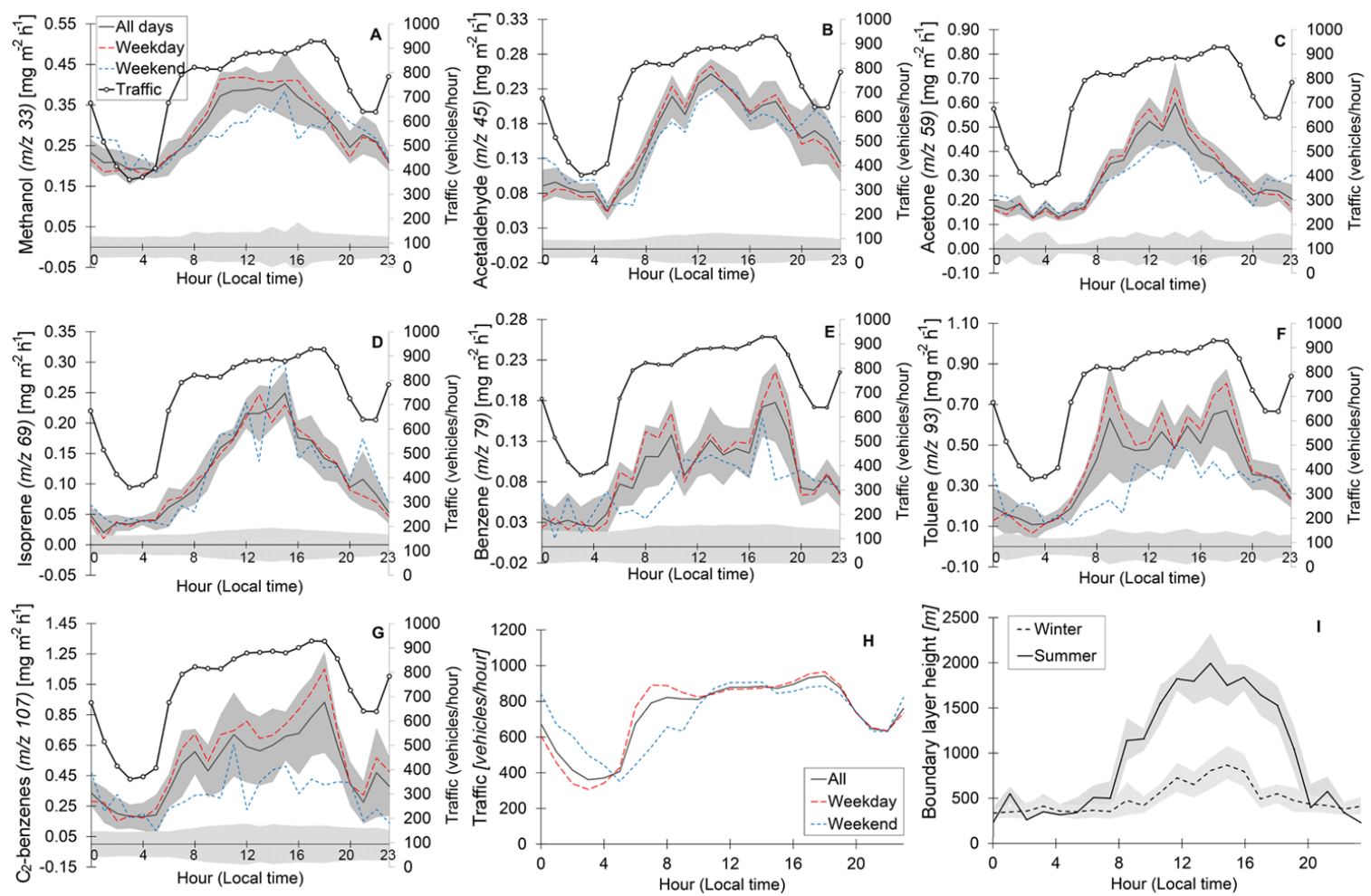

Figure 2.

the footprint function and includes a weighting function to describe the influence of a unit point source on the flux from any surface location $(x, y)$. In order to compare VOC fluxes with estimated emissions from the LAEI, a $9 \mathrm{~km}^{2}$ section of the $1 \mathrm{~km}^{2}$ resolution OS grid system was used, which on average included $90 \%$ of the footprint contribution to all measured fluxes. This area was limited to central London and partially included the following boroughs: Westminster (squares 1, 4, 5 and 7), Southwark (2, 3 and 6), Camden (8) and the City of London (9) (Fig. 1).

\section{Results and discussion}

\subsection{Diurnal profiles of VOC fluxes and concentrations}

Average diurnal cycles of measured VOC fluxes and mixing ratios are shown in Fig. 2 with descriptive statistics for all the data summarised in Table 2. Largest median (interquartile range in parenthesis) fluxes per day were from $\mathrm{C}_{2}$-benzenes and toluene, with 7.86(0.9221.8) $\mathrm{kg} \mathrm{km}^{-2} \mathrm{~d}^{-1}$ and $7.26(1.83-15.3) \mathrm{kg} \mathrm{km}^{-2} \mathrm{~d}^{-1}$ respectively, followed by oxygenated compounds, i.e. methanol with $6.37(2.99-10.0) \mathrm{kg} \mathrm{km}^{-2} \mathrm{~d}^{-1}$, acetaldehyde $3.29(1.52-5.62) \mathrm{kg} \mathrm{km}^{-2} \mathrm{~d}^{-1}$ and acetone $5.24(2.33-$ $9.62) \mathrm{kg} \mathrm{km}^{-2} \mathrm{~d}^{-1}$. Isoprene and benzene showed the smallest median fluxes with $2.14(0.56-4.85) \mathrm{kg} \mathrm{km}^{-2} \mathrm{~d}^{-1}$ and $1.78(0.06-4.34) \mathrm{kg} \mathrm{km}^{-2} \mathrm{~d}^{-1}$ respectively. The highest median mixing ratios were of the oxygenated compounds methanol (7.3 (6.8-7.9) ppb), acetone $(0.95(<\mathrm{LoD}-$ $1.36) \mathrm{ppb})$ and acetaldehyde $(0.82(0.59-1.13) \mathrm{ppb})$, followed by aromatics $\left(\mathrm{C}_{2}\right.$-benzenes, toluene and benzene), and isoprene.

Oxygenated compounds commonly have relatively long atmospheric lifetimes and widespread origin including anthropogenic and biogenic sources and photochemistry, resulting in elevated concentrations and less pronounced diurnal profiles (Atkinson, 2000). Most VOC fluxes and concentrations were comparable to or lower than those previously observed in London (Langford et al., 2010b) and other UK cities (Langford et al., 2009), although $\mathrm{C}_{2}$-benzene fluxes and concentrations, as well as isoprene and benzene concentrations, were slightly higher. The discrepancy in isoprene and benzene concentrations is consistent with photochemical loss during transport to the higher measurement height of the previous studies. Compared to other cities such as Houston Texas (Park et al., 2010) and Mexico City (Velasco et al., 2005), VOC fluxes and concentrations were lower with the exception of $\mathrm{C}_{2}$-benzenes, which were comparable or higher; however, it must be noted that $\mathrm{C}_{2}$-benzenes in this study represent the sum of multiple VOC species. Unlike the other studies cited, Park et al. (2010) use relaxed eddy accumulation to measure VOC fluxes and hence the data obtained are not directly comparable with measurements made by ECbased methods. 

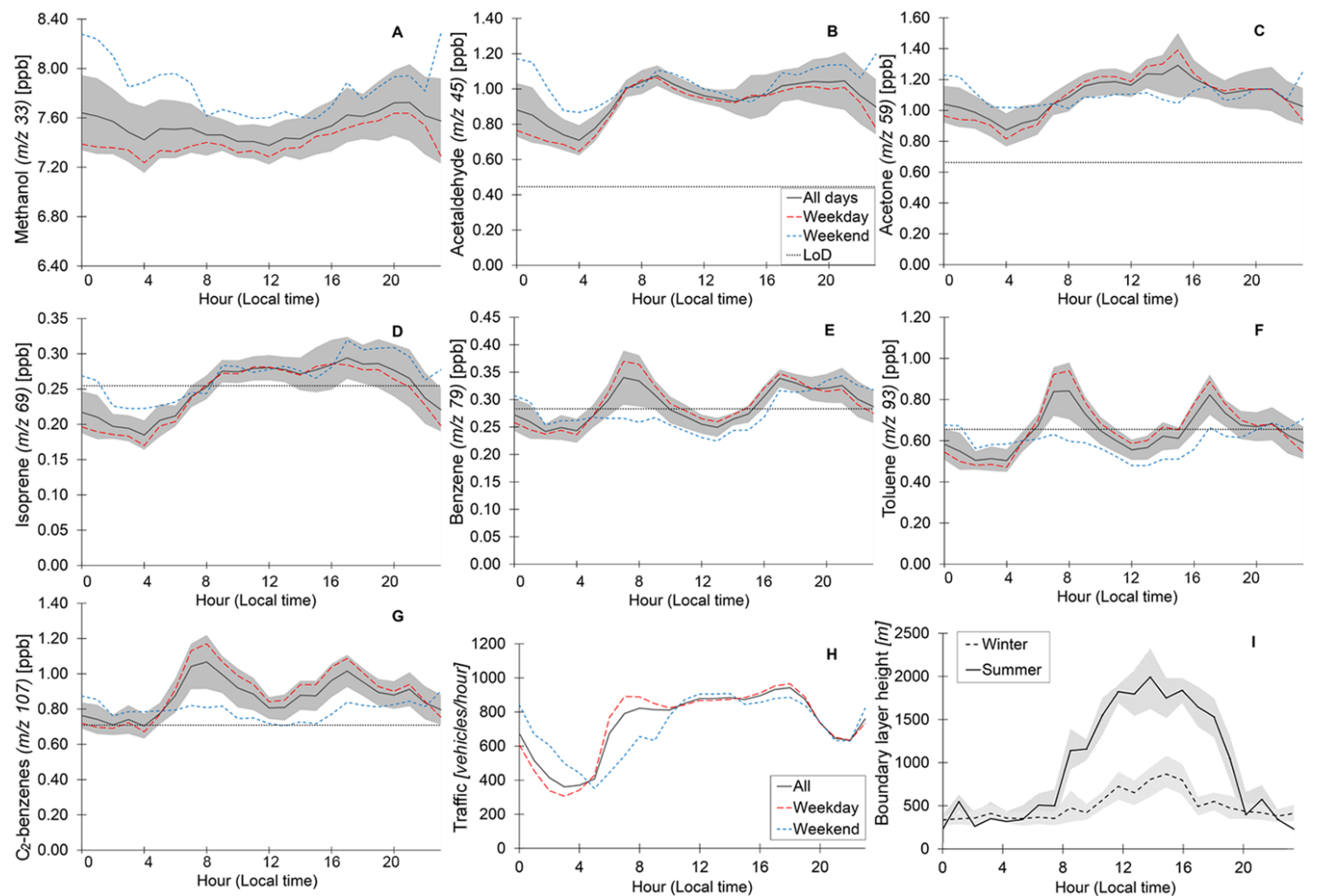

Figure 2. Part 1: average diurnal profiles in local time for selected VOC fluxes $\left(\mathrm{mg} \mathrm{m}^{-2} \mathrm{~h}^{-1}\right)$ separated into all days, weekdays (red dashed line) and weekends (blue dotted line) with traffic density (vehicles $\mathrm{h}^{-1}$ ), detection limit (patterned area) and upper and lower confidence intervals (shaded area). Traffic density (with weekday and weekend) and boundary layer mixing height (for summer and winter) are shown in separate panels. Compounds are $m / z 33$ (methanol), $m / z 45$ (acetaldehyde), $m / z 59$ (acetone/propanal), $m / z$ 69 (isoprene/furan), $m / z 79$ (benzene), $m / z 93$ (toluene) and $m / z 107$ ( $\mathrm{C}_{2}$-benzenes). Part 2: average diurnal profiles in local time for selected VOC mixing ratios (ppb) separated into all days, weekdays (red dashed line) and weekends (blue dotted line) with detection limit (dotted line) and upper and lower confidence intervals (shaded area). Traffic density (with weekday and weekend) and boundary layer mixing height (for summer and winter) are shown in separate panels. Compounds are $m / z 33$ (methanol), $m / z, 45$ (acetaldehyde), $m / z$ 59 (acetone/propanal), $m / z 69$ (isoprene/furan), $m / z 79$ (benzene), $m / z 93$ (toluene) and $m / z 107\left(\mathrm{C}_{2}\right.$-benzenes). The mixing ratio axes start from 0 apart from that of methanol, which begins at $6.4 \mathrm{ppb}$ due to the high atmospheric background.

Diurnal profiles of aromatic fluxes and concentrations presented two clear rush hour peaks during the morning and evening (07:00-10:00 and 17:00-20:00 local time). Concentration peaks are thought to be linked to additional advection of traffic-related pollution from larger commuter roads outside of the city centre, as well as boundary layer effects and photochemistry. VOC concentration measurements at canopy height can be affected by boundary layer depth (Vilà-Guerau de Arellano et al., 2009). The rush hour emission peaks mostly coincide with the boundary layer expansion and collapse and therefore the effect of each factor cannot be separated. The morning concentration peak was slightly higher than the evening peak across traffic-related species even though fluxes tended to be larger during the evening rush hour. Morning emissions enter a shallow nocturnal boundary layer leading to relatively larger concentrations compared to higher afternoon emissions entering a developed boundary layer leading to relatively lower concen- trations. This enhanced dilution effect is found more often during summer when the boundary layer mixing height is higher (Fig. 2). Therefore, the regression analyses below only refer to data from August (cf. Sect. 3.1.2 for comparisons with winter). Furthermore, increased photochemical degradation during the day removes VOCs, further contributing to the midday minimum in mixing ratios. The diurnal flux profiles of methanol, acetone, isoprene and to a smaller extent acetaldehyde showed one large peak just after midday (approx. 13:00 local time), which was only reflected in the concentration profiles of acetone and isoprene. Acetaldehyde concentrations presented a slight double peak similar to mixing ratios of aromatics. Methanol has a relatively long atmospheric lifetime and therefore high background concentrations, and hence mixing ratios showed no distinct diurnal profile. 


\subsubsection{Correlations with possible controlling variables of VOC fluxes and concentrations}

Aromatic compound fluxes closely followed the diurnal profile of traffic density with good correlations $\left(R^{2}=0.51-0.92\right.$, $p<0.05)$ and slightly lower fluxes observed on the weekends. In central urban areas in the UK, traffic densities and therefore traffic-related VOC fluxes - increase steadily throughout the day, with discernible peaks during morning, midday and evening (Nemitz et al., 2002), which was also observed in this study. Previous studies have shown that the Marylebone Road traffic count point can be used as a proxy representative of traffic flows throughout central London (Helfter et al., 2011).

The aforementioned concentration dilution due to boundary layer expansion resulted in negative correlations between boundary layer height and aromatic mixing ratios in August $\left(R^{2}=0.33-0.56, p<0.01\right)$. As aromatic compound fluxes slightly dipped around midday, the mixing ratios were further diluted by the deep boundary layer. The above evidence suggests that traffic-related emissions were the main contributors to fluxes and mixing ratios of aromatic compounds. Acetone and isoprene showed peak midday fluxes, which maintained daytime mixing ratios and produced positive correlations with boundary layer height $\left(R^{2}=0.16\right.$ and 0.59 respectively; $p<0.01$ ). De Gouw et al. (2005) reported that changes in boundary layer meteorology could result in greater effects on observed concentrations of methanol and acetone due to their high background values. The mixing ratios of these compounds are, therefore, likely dominated by advected pollution rather than the local flux. Possibly a combination of boundary layer and photochemical effects were seen with methanol mixing ratios wherein correlations with mixing height were negative $\left(R^{2}=0.70, p<0.01\right)$, whereas acetone and isoprene fluxes seemed to be sufficiently high during the day to maintain peak midday mixing ratios (Fig. 3 example of isoprene). Vehicle emissions may have contributed to acetaldehyde and isoprene levels directly or indirectly (Fig. 3 example of isoprene), because correlations of fluxes with traffic density were fairly high $\left(R^{2}=0.60\right.$ and 0.46 respectively; $p<0.05$ ). The diurnal concentration profile of acetaldehyde to some degree mimicked those of traffic-related compounds reflecting a slight double peak.

VOC fluxes and concentrations plotted as a function of PAR showed strong daytime (defined as 06:00 to 18:00 local time) correlations for methanol, acetaldehyde and isoprene fluxes $\left(R^{2}=0.71-0.78, p<0.001\right)$ and concentrations $\left(R^{2}=0.66-0.83, p<0.001\right)$. Plotted as a function of temperature, high correlations with methanol, acetaldehyde and isoprene fluxes were seen $\left(R^{2}=0.75,0.63\right.$ and 0.94 respectively; $p<0.001$ ), whereas only methanol and acetone concentrations showed higher correlations with temperature $\left(R^{2}=0.64\right.$ and 0.81 respectively; $\left.p<0.001\right)$. Methanol fluxes correlated linearly with temperature $\left(R^{2}=0.75\right.$, $p<0.001)$, but acetaldehyde and isoprene fluxes $\left(R^{2}=0.64\right.$

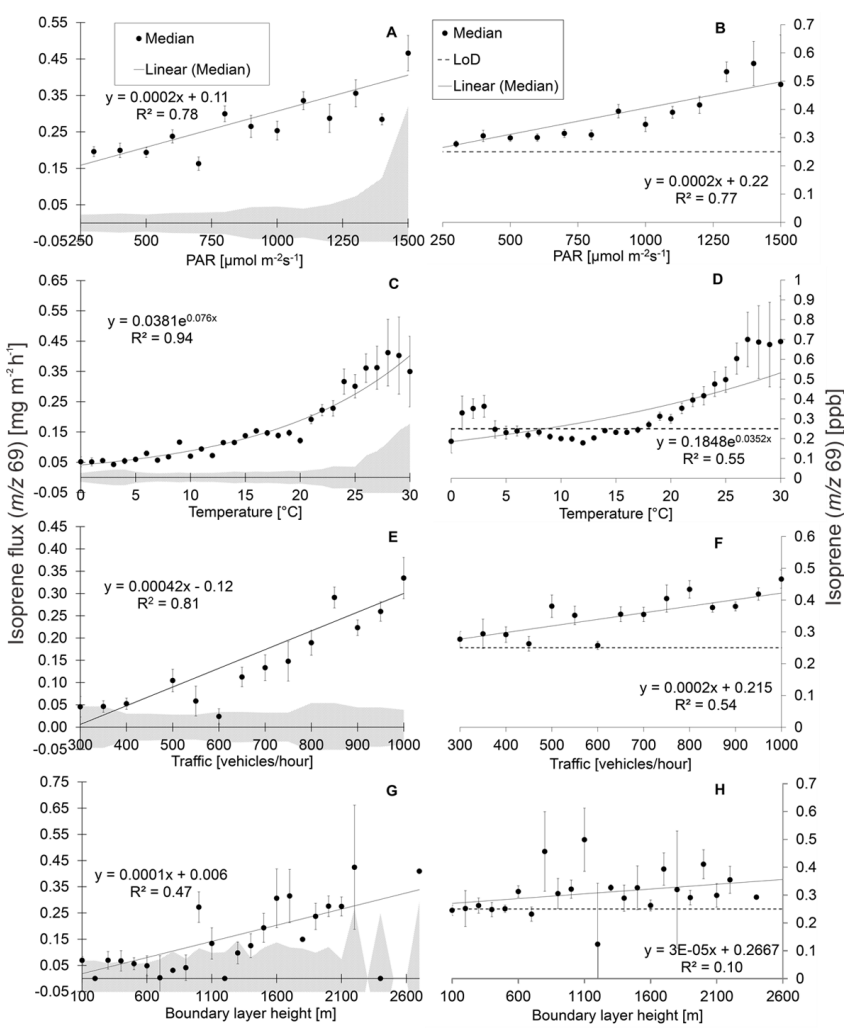

Figure 3. Examples, using isoprene, of averaged VOC fluxes (left) and mixing ratios (right) as a function of photosynthetically active radiation (PAR) $\left(\mu \mathrm{mol} \mathrm{m}{ }^{-2} \mathrm{~s}^{-1}\right)$, temperature $\left({ }^{\circ} \mathrm{C}\right)$, traffic density (vehicles $\mathrm{h}^{-1}$ ) and boundary layer mixing height $(\mathrm{m})$ based on 25 min VOC means with linear or exponential regressions, formulae, $R^{2}$ values and detection limit (shaded area for fluxes and dashed line for mixing ratios).

and $0.94 ; p<0.01)$ and mixing ratios $\left(R^{2}=0.45\right.$ and 0.55 ; $p<0.01)$ had exponential relationships with temperature (Fig. 3 example of isoprene). The relationships of mixing ratios with PAR and temperature for these compounds improved greatly when night-time values were excluded (defined as PAR $<100 \mu \mathrm{mol} \mathrm{m}^{-2} \mathrm{~s}^{-1}$ ) and when times of low temperature $\left(<5^{\circ} \mathrm{C}\right)$ were excluded. This indicates either separate source contributions or effects of boundary layer meteorology in these instances, whereby increased mixing ratios of these compounds with low PAR and temperature likely result from reduced dilution within a shallow boundary layer, e.g. at night or in winter, or from possible contributions of anthropogenic sources such as exhaust emissions, which are largely independent of light and temperature. Increases in concentrations due to high PAR and temperature suggest biogenic sources, increased evaporative emissions and/or secondary atmospheric formation driven by oxidation of precursor hydrocarbons (Singh et al., 1994). Oxygenated compounds have a variety of different source contributions such as tailpipe emissions, evaporative emissions from fuel and solvents, direct emissions from plants, leaf decomposi- 

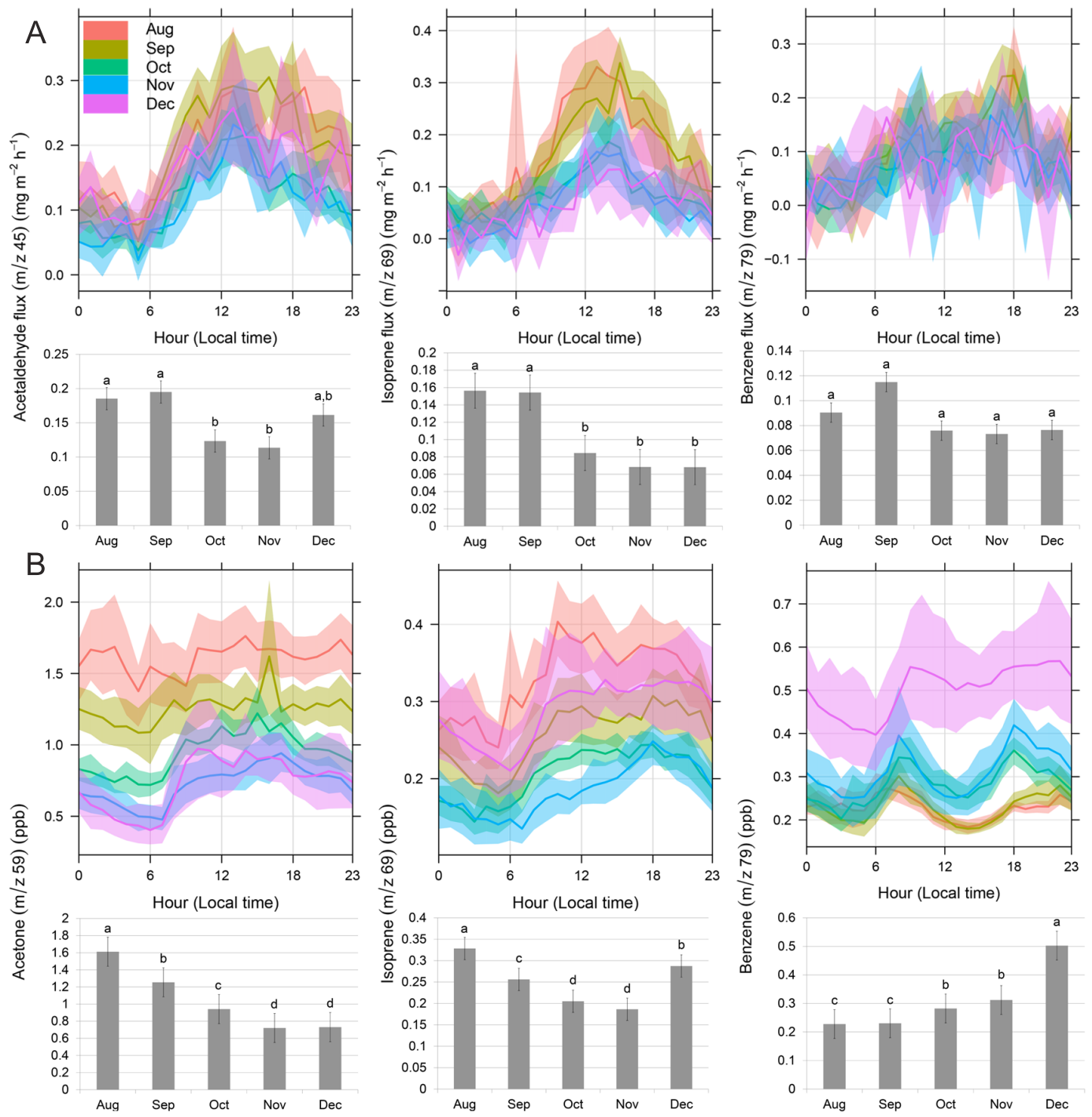

Figure 4. Diurnal profiles by month with confidence intervals and bar charts showing hourly averages for the respective month and representative compound (top) fluxes $\left(\mathrm{mg} \mathrm{m}^{-2} \mathrm{~h}^{-1}\right)(\mathrm{m} / z$ 45, 69 and 79) and (bottom) mixing ratios $(\mathrm{ppb})(\mathrm{m} / z$ 59, 69 and 79). Letters $(\mathrm{a}-\mathrm{d})$ indicate statistically significant subgroups using Tukey's Honestly Significant Difference post hoc test.

tion and secondary atmospheric production (Langford et al., 2009 , and references therein).

Modelling studies have indicated that the contribution of secondary atmospheric formation to VOC concentrations could be more significant, especially in urban areas, during summer, i.e. with high PAR and temperatures (de Gouw et al., 2005; Harley and Cass, 1994). Acetone fluxes reached a maximum when PAR and temperature were around $1000 \mu \mathrm{mol} \mathrm{m} \mathrm{m}^{-2} \mathrm{~s}^{-1}$ and $15-20^{\circ} \mathrm{C}$ respectively before declining, whereas mixing ratios increased exponentially with light and temperature. These observations resemble measurements over forest canopies (e.g. Schade and Goldstein, 2001). Aromatic compound concentrations and fluxes showed no correlations with PAR. Weak negative correlations were seen between aromatic concentrations and temperature, and weak positive correlations were seen between fluxes and temperature likely due to increased thermal mixing. The observed light and temperature responses associated with isoprene fluxes and mixing ratios in August and September can be explained by biogenic sources (cf. Sect. 3.1.3).

\subsubsection{Seasonal variability of VOC sources and meteorology}

Most compounds showed larger fluxes in August and September than in October, November and December with the exception of acetaldehyde, which also showed increased fluxes in December (Fig. 4 top). Increased acetaldehyde fluxes in December may have resulted from an additional source, such as domestic biomass burning (Andreae and Mer- 
Table 3. Summary of site meteorology by month in central London during 2012.

\begin{tabular}{lrrrlrr}
\hline Parameter & $\begin{array}{r}\text { Data coverage } \\
(\%)\end{array}$ & $\begin{array}{r}\text { Median } \\
\text { stability }(\zeta)\end{array}$ & $\begin{array}{r}\text { Wind speed } \\
\left(\mathrm{m} \mathrm{s}^{-1}\right)\end{array}$ & $\begin{array}{l}\text { Dominant wind } \\
\text { direction }(\%)\end{array}$ & $\begin{array}{r}\text { Footprint* } \\
\text { length }(\mathrm{m})\end{array}$ & $\begin{array}{r}\text { Footprint } \\
\text { width }(\mathrm{m})\end{array}$ \\
\hline Aug & 67 & -0.0086 & 3.3 & $\mathrm{~S}(54)$ & 2417 & 1355 \\
Sep & 83 & -0.0154 & 3.2 & $\mathrm{~W}(48)$ & 1285 & 880 \\
Oct & 89 & -0.0006 & 3.5 & $\mathrm{~S}(29)$ & 2624 & 1327 \\
Nov & 51 & -0.0037 & 3.4 & $\mathrm{~S}(53)$ & 2329 & 1156 \\
Dec & 40 & 0.0047 & 3.4 & $\mathrm{~N}(32)$ & 1804 & 990 \\
\hline
\end{tabular}

* Calculated 2-D description of the oval footprint according to the KM model. Length parameter is the length between the point nearest to the sensor where the crosswind-integrated footprint function reaches $1 \%$ of its maximum value to the point where it drops below $1 \%$ of the maximum value.

let, 2001; Lipari et al., 1984), although there are only few residential buildings in this area of London. Only toluene fluxes in September were significantly higher than in other months and benzene fluxes showed no significant seasonal differences. Seasonal variability in fluxes was likely due to increased emissions in summer, especially for compounds with biogenic and secondary atmospheric sources. Average monthly meteorological parameters are summarised in Table 3 .

Mixing ratios of aromatics were generally lower in summer and highest in December (Fig. 4 bottom). This is likely due to less dilution effects in winter when the boundary layer is shallow or from advection of additional sources such as heating, since there was no increase in fluxes. Generally, in summer the boundary layer mixing height is higher and collapses later in the evening which maintains the dilution effect for VOC concentrations. In winter the average boundary layer mixing height is lower. It develops later in the morning and collapses earlier in the afternoon, which could increase not only overall VOC mixing ratios but also individual maxima, e.g. during rush hours. Comparing average diurnal profiles of compound mixing ratios with boundary layer height during summer and winter shows that aromatic compound concentrations were associated with negative correlations in summer (cf. Sect. 3.1.1) which became positive during winter $\left(R^{2}=0.10-0.33, p<0.01\right)$, while fluxes maintained positive correlations with boundary layer height regardless of season. This suggests that boundary layer effects may be an important driver of increased concentrations in winter. Furthermore, traffic counts for the Congestion Charge Zone in central London indicate lower monthly average vehicle counts in December (Department for Transport, 2014). Oxygenated compounds and isoprene mixing ratios were highest in summer with the exception of acetone, which increased in December likely from boundary layer effects, reduced photochemical degradation or advection. Correlations of mixing ratios and fluxes with boundary layer height were positive for acetone and isoprene during summer and winter, whereas methanol and acetaldehyde presented negative correlations during summer, indicating stronger dilution effects (cf. Sect. 3.1.1).
Increased summer mixing ratios of oxygenated compounds and isoprene indicated a temperature dependent, possibly biogenic source contribution. While biogenic emissions may be advected from outside of the city, the concurrent increase in isoprene fluxes suggests the source to be largely local to the flux footprint. The temperature-dependent fraction of observed isoprene mixing ratios, which may include advected pollution, was estimated using the isoprene temperature response function from Fig. 9 in Langford et al. (2010b), which estimated a 30 and $20 \%$ contribution in August and September respectively. These values were significantly higher than for isopentane, a non-biogenic compound available from the Automatic Hydrocarbon Network, to which the same analysis was applied. The temperaturedependent component of isoprene in October, November and December showed no significant difference to that of isopentane, suggesting the biogenic component was reduced or absent at lower temperatures. High correlations of $m / z 69$ with light and temperature during August and September indicate that isoprene was the likely major component during these months; however, during the rest of the period the contribution of additional compounds such as furan and other alkenes at that mass may have increased, thereby overestimating the isoprene signal (Yuan et al., 2014).

\subsubsection{Modelling the biogenic isoprene contribution in London}

An attempt was made to model the biogenic isoprene component during August and September using the light and temperature algorithms of Guenther et al. (1995), hereafter termed G95. The foliar-emissions-based model calculates VOC fluxes as follows:

$F=D \times \varepsilon \times \gamma$,

where $D$ is the foliar density ( $\mathrm{kg}$ dry matter $\left.\mathrm{m}^{-2}\right), \varepsilon$ is an ecosystem-dependent base emission rate $\left(\mu \mathrm{g} \mathrm{C} \mathrm{m}^{-2} \mathrm{~s}^{-1}\right.$ normalised to a PAR flux of $1000 \mu \mathrm{mol} \mathrm{m} \mathrm{m}^{-2} \mathrm{~s}^{-1}$ and leaf temperature of $303.15 \mathrm{~K}$ ) and $\gamma$ is a dimensionless activity adjustment factor accounting for the effects of PAR and leaf temperature. Ambient air temperature and PAR measurements 
(a)
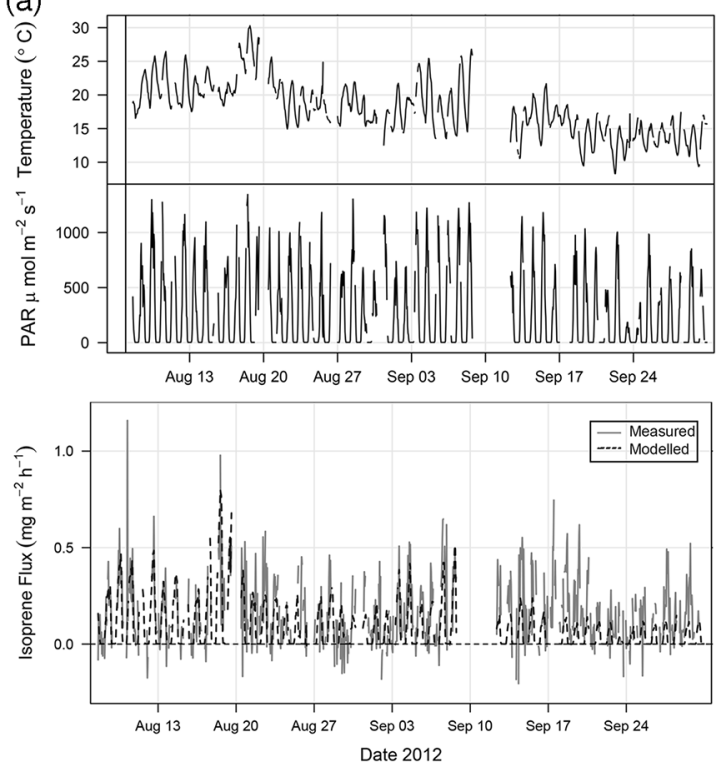

(b)

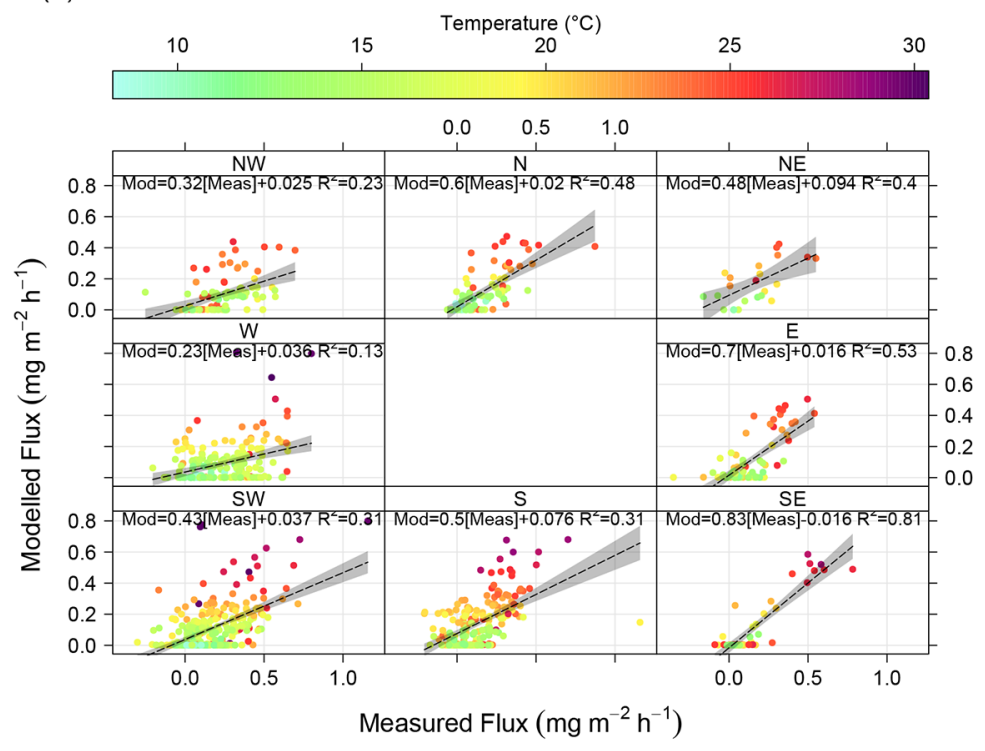

Figure 5. (a) Time series of both measured (grey) and modelled (black) fluxes, as well as PAR and temperature measurements for August and September 2012. (b) Correlation between modelled and measured isoprene fluxes $\left(\mathrm{mg} \mathrm{m}^{-2} \mathrm{~h}^{-1}\right)$ by wind direction using the G95 algorithm with temperature as a third variable, ordinary least squares regression lines, 99th confidence intervals, formulae and $R^{2}$ value.

were used to calculate the light- and temperature-controlled parameters $C_{\mathrm{L}}$ and $C_{\mathrm{T}}$ for $\gamma$, where

$\gamma=C_{\mathrm{L}} \times C_{\mathrm{T}}$.

The slope of the linear regression of the measured total isoprene flux and $\gamma$ provided an emission factor in $\mathrm{mg} \mathrm{m}^{-2} \mathrm{~h}^{-1}$, which was converted to $\mu \mathrm{g} \mathrm{g}^{-1} \mathrm{~h}^{-1}$ by dividing by the foliar density $\left(D=0.129 \mathrm{~kg} \mathrm{~m}^{-2}\right)$. The foliar density was estimated using the total tree leaf area as seen from visible satellite imagery within the flux footprint and tree leaf dry weight for representative species commonly planted in the area, such as Platanus $x$ acerifolia (City of Westminster, 2009), that are also high isoprene emitters (Geron et al., 1994). The resulting base emission rate $\varepsilon$ from the measured fluxes was $6.5 \mu \mathrm{g} \mathrm{g}^{-1} \mathrm{~h}^{-1}$, which compares well with the figure given in the literature $\left(5 \mu \mathrm{g} \mathrm{g}^{-1} \mathrm{~h}^{-1}\right)$ for cities in a cool climate (Guenther et al., 1995). For details of this calculation, see Sect. B in the Supplement. These estimates are representative of the biogenic isoprene fluxes from a highly heterogeneous canopy within the flux footprint, including both high- and low-isoprene-emitting species as well as low average foliar density due to the sparse distribution of urban roadside and park trees. Green areas, as defined on the OS map, comprised $9 \%$ of the total grid area and were evenly distributed across the $9 \mathrm{~km}^{2}$. Only grid square 1 included a large green area of 23 ha (St. James' Park). The National Forest Inventory (NFI, http://www.forestry.gov.uk/forestry/ hcou-54pg9u) of England only included $4.4 \%$ green areas within the grid selection (NFI). The NFI excluded individual trees in parks and avenues, which can encompass up to $50 \%$ of trees maintained by the local authority in central London (City of Westminster, 2009).

Figure 5 shows that the modelled isoprene fluxes using the calculated base emission rate compared well with the measured fluxes by wind direction. Linear regressions from wind directions that have a strong anthropogenic component are lower, e.g. W $\left(R^{2}=0.13, p<0.001\right)$, than from those areas dominated by biogenic sources, e.g. SE $\left(R^{2}=\right.$ $0.81, p<0.001$ ), due to the nearby Temple Gardens. Modelled emissions seemingly underestimated observed isoprene fluxes since these included the traffic component; however, it appears that biogenic isoprene represents a detectable source contribution in summer.

\subsection{VOC / VOC correlations and ratios}

Correlations of VOC/VOC fluxes $\left(R^{2}=0.40-0.62\right.$, $p<0.001)$ indicated two groups of compounds with good correlations within each group, i.e. compounds related to traffic sources, such as aromatics, and oxygenated and biogenic compounds, such as methanol, acetone and isoprene (Fig. 6 top). Correlations of VOC / VOC concentrations $\left(R^{2}=0.13-0.84, p<0.001\right)$ showed the highest correlations between traffic-related compounds $\left(R^{2}=0.45-0.84\right.$, $p<0.001)$ and good correlations between the oxygenated and biogenic compounds $\left(R^{2}=0.55-0.69, p<0.001\right)$ (Fig. 6 bottom). High correlations between oxygenated VOCs could indicate source commonality or formation mechanisms that depend on similar environmental factors. Scatter plots between aromatic compounds and isoprene/oxygenated compounds tend to show bimodal distributions indicating 

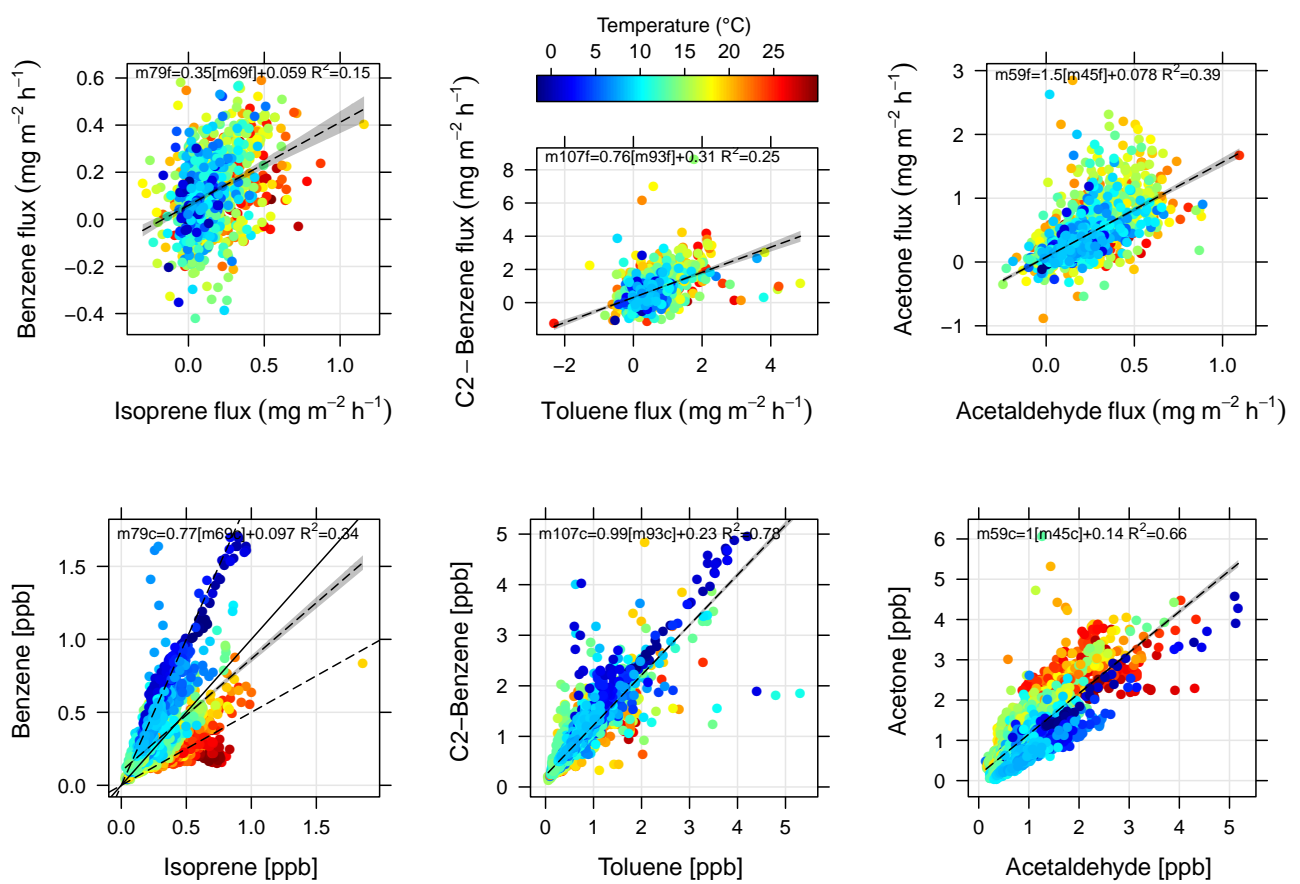

Figure 6. Selected scatter plots of representative correlations of VOC / VOC fluxes (top) and mixing ratio (bottom) with temperature as a third variable showing an example of bimodal, strong linear and medium linear correlations as commonly seen in the mixing ratio correlations with $R^{2}$ values, $1: 1$ line, $1: 2$ and $2: 1$ lines for the bimodal example in the bottom left panel.

separate source contributions. Using temperature or, to a smaller extent, PAR as a third variable highlights a temperature or light dependency of the second source supporting the existence of additional biogenic and/or atmospheric sources. In the example of isoprene against benzene the relationship changes with temperature from $2: 1$ to $1: 2$.

\subsubsection{Benzene to toluene ratios}

Benzene to toluene $(b / t)$ ratios can help identify source types and changes in ratios can indicate the photochemical age of an air mass as toluene reacts at a faster rate with $\mathrm{OH}$ in the atmosphere, assuming sufficient $\mathrm{OH}$ concentrations to drive the reaction (Warneke et al., 2007). Median (and interquartile range, IQR) $b / t$ flux ratios were $0.21(0.02-0.43)$ and median (IQR) $b / t$ concentration ratios were $0.45(0.39-0.48)$. Individual maxima and minima were seen in the $b / t$ concentration ratios, examples of which are discussed below.

The observed ratios compared well with those of other European cities, which showed $b / t$ concentration ratios of 0.35 in Zurich (Heeb et al., 2000), 0.57 in Manchester (Langford et al., 2009), 0.57-0.63 in London (Valach et al., 2014) and 0.1 at $190 \mathrm{~m}$ above London (Langford et al., 2010b). Trafficrelated emissions are considered to be an important source of benzene and toluene in London. $B / t$ exhaust emission ratios based on derived yearly emissions in other megacities, such as Mexico City, were found to be 0.4 (Zavala et al., 2006), which agreed well with observed $b / t$ concentration ratios in this study. Airborne flux measurements over Mexico City have shown average $b / t$ flux ratios of 0.31 with lower ratios of 0.07 to 0.1 over industrial areas due to increased toluene emissions from industrial processes (Karl et al., 2009; Velasco et al., 2007). Evaporative emissions from gasoline or direct industrial toluene emissions may have contributed to the lower $b / t$ flux ratios in London. Furthermore, low $b / t$ concentration ratios of 0.26 from diesel emissions have been reported (Corrêa and Arbilla, 2006). The widespread use of diesel fuel in London (buses, taxis and some cars and trains) and diesel emissions from roads which exclude passenger cars, such as Oxford Street (approx. $1.3 \mathrm{~km} \mathrm{~W}$ from the measurement site), or central railway nodes, such as Waterloo railway station $(1 \mathrm{~km} \mathrm{~S})$, may have affected $b / t$ ratios.

Wind speed and direction can play a role for $b / t$ concentration ratios by transporting pollution over longer distances allowing more time to react with or exposure to higher $\mathrm{OH}$ concentrations, thus increasing the ratio. An example of this (Fig. 7) was seen on 12 August when median (IQR) $b / t$ concentration ratios reached $0.5(0.45-0.56)$ with stronger SE winds (mean $3.67 \mathrm{~m} \mathrm{~s}^{-1}$ ) possibly advecting pollution from Benelux/northern Europe, whereas on 9 August median $b / t$ ratios were $0.34(0.30-0.38)$ with low wind speeds (mean $1.28 \mathrm{~m} \mathrm{~s}^{-1}$ ), indicating higher contributions of local sources (i.e. $60 \%$ London influence) (Bohnenstengel et al., 2015). On both days $\mathrm{OH}$ concentrations above London were around $1.25 \times 10^{6}$ molecules $\mathrm{cm}^{-3}$ and $b / t$ flux ratios were not significantly different, making pollution advection 


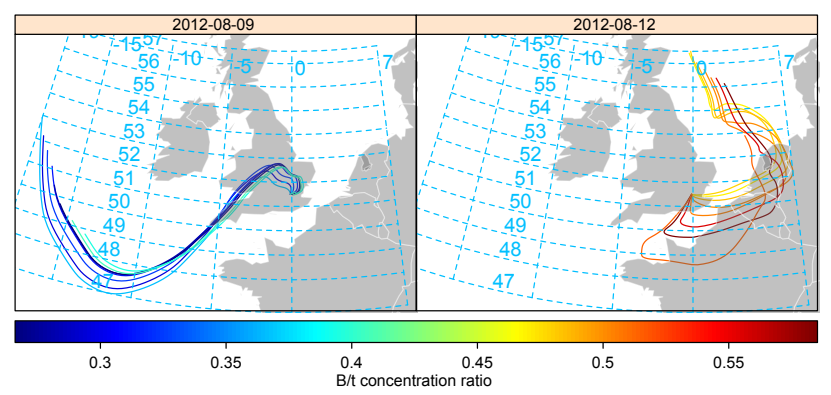

B/t ratio 9th August B/t ratio 12th August
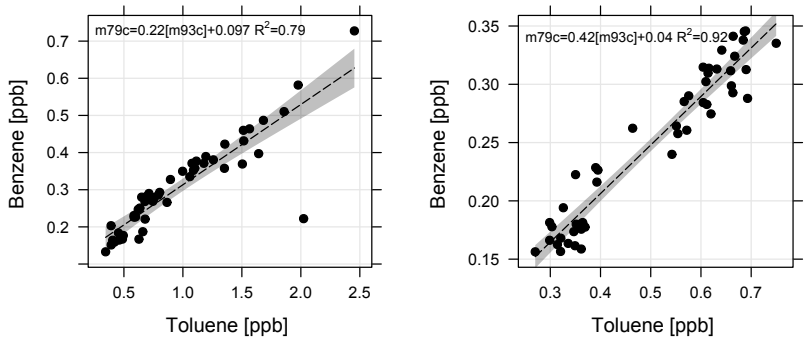

Figure 7. Top: $24 \mathrm{~h}$ back trajectories from the NOAA HYSPLIT trajectory model during selected days in August 2012 corresponding to periods of low (left) and high (right) benzene/toluene concentration ratios. Daily release in $3 \mathrm{~h}$ intervals $(10 \mathrm{~m}$ height $)$ for $24 \mathrm{~h}$ prior. Bottom: scatter plots showing benzene-to-toluene concentration ratios during 9 August 2012 (left) and 12 August 2012 (right) with linear regression with 95th confidence interval, regression equation and coefficient $\left(R^{2}\right)$.

a likely cause of the observed difference (L. Whalley, personal communication 2014). Calculated back trajectories using the HYSPLIT trajectory model (Hybrid Single Particle Lagrangian Integrated Trajectory Model; Draxler and Rolph, 2008) were run at $3 \mathrm{~h}$ intervals starting at ground-level $(10 \mathrm{~m})$ from London and propagated $24 \mathrm{~h}$ backwards in time. During periods of high $b / t$ ratios the back trajectories indicated that air had passed over continental Europe in the past $24 \mathrm{~h}$, during which freshly emitted pollutants would have been entrained.

The median monthly $b / t$ flux ratio during the measurement period stayed between 0.18 and 0.26 , which is to be expected since only local fluxes were detected; however, the median (IQR) monthly $b / t$ ratio for concentrations steadily increased from $0.41(0.36-0.47)$ to $0.62(0.55-0.70)$ from August to December. Advected pollution from mainland Europe may be common in winter or biomass burning may play a greater role in colder months, as this is associated with higher $b / t$ ratios, e.g. 1.67 (Lemieux et al., 2004), due to the different fuel combustion emission profile. Furthermore, $\mathrm{OH}$ concentrations in London are often below the detection limit during winter (Bohnenstengel et al., 2015), resulting in less local photochemical removal during the winter months.

Median (IQR) concentration ratios for benzene to $\mathrm{C}_{2}$ benzenes were $0.31(0.28-0.33)$ and toluene to $C_{2}$-benzenes were $0.72(0.63-0.81)$, which both agree with previous values and suggest that these masses are indeed the ascribed traffic-related compounds (Heeb et al., 2000; Warneke et al., 2001).

\subsubsection{VOC-to- $\mathrm{CO}_{2}$ correlations and ratios}

Good correlations were found among averaged VOC fluxes plotted as a function of averaged $\mathrm{CO}_{2}$ fluxes, which were measured concurrently at the site $\left(R^{2}=0.03-0.81\right.$, $p<0.001)$. Traffic-related compounds were initially among the lowest correlations with $\mathrm{CO}_{2}$ fluxes $\left(R^{2}=0.03-0.48\right.$, $p<0.01)$. However, when points of peak $\mathrm{CO}_{2}$ fluxes were removed, the correlations with traffic-related VOC fluxes increased significantly to $R^{2}=0.65-0.91(p<0.001)$. Presumably, the initial poor correlations resulted from an additional strong $\mathrm{CO}_{2}$ source, such as vents from gas-fired boilers in nearby buildings, which have a lower source commonality with aromatic VOCs, i.e. a lower $\mathrm{VOC} / \mathrm{CO}_{2}$ emission ratio than that of traffic emissions for aromatic compounds. The LAEI indicates that $\mathrm{VOC} / \mathrm{CO}_{2}$ flux ratios for benzene are higher for traffic emission sources (i.e. $2 \times 10^{-5}$ ) than gas sources (i.e. $0.6 \times 10^{-5}$ ) within the flux footprint. The improved correlations are greater for traffic-related compounds due to the limited range of source types contributing to this group compared with oxygenated/biogenic compounds. The regression coefficient $\left(R^{2}\right)$ of benzene with $\mathrm{CO}_{2}$ fluxes increased from 0.48 to 0.91 , whereas for isoprene fluxes the increase was small, i.e. 0.68 to 0.70 (Fig. 8), as isoprene has a range of different sources of which only a few are commonly shared sources with $\mathrm{CO}_{2}$.

The presence of a strong separate $\mathrm{CO}_{2}$ source within the flux footprint is supported by the high averaged VOC-to$\mathrm{CO}_{2}$ concentration correlations for traffic-related compounds $\left(R^{2}=0.92-0.96, p<0.001\right)$. This differs from the fluxes, which are influenced only by sources in the flux footprint, where one strong point source with a different emission ratio may have a larger effect on emission rates of one compound but not the other. Concentrations are influenced by advected pollution from outside the flux footprint for both $\mathrm{CO}_{2}$ and VOCs, where shared emission sources with relatively higher $\mathrm{VOC} / \mathrm{CO}_{2}$ ratios are more widespread. Averaged VOC to $\mathrm{CO}_{2}$ concentration correlations were lower with the oxygenated/biogenic compounds $\left(R^{2}=<0.71-0.90, p<0.05\right)$.

Median VOC $/ \mathrm{CO}_{2}$ flux ratios ranged from $1.7 \times 10^{-5}$ to $7.7 \times 10^{-5}\left(\mathrm{mg} \mathrm{m}^{-2} \mathrm{~h}^{-1} / \mathrm{mg} \mathrm{m}^{-2} \mathrm{~h}^{-1}\right)$ with isoprene and benzene showing low ratios due to their low fluxes and toluene and $\mathrm{C}_{2}$-benzenes showing high ratios. Highest flux ratios for all compounds were with $\mathrm{W}$ winds, whereas lowest for biogenic compounds with $\mathrm{N}$ and for traffic-related compounds $\mathrm{S}$ wind directions. Flux ratios declined towards December as $\mathrm{CO}_{2}$ fluxes increased and VOC fluxes decreased. Similarly, VOC $/ \mathrm{CO}_{2}$ concentration ratios were between $0.45 \times 10^{-6}$ and $14.6 \times 10^{-6}(\mathrm{ppb} / \mathrm{ppb})$ with isoprene and benzene representing the lowest and methanol and acetone 

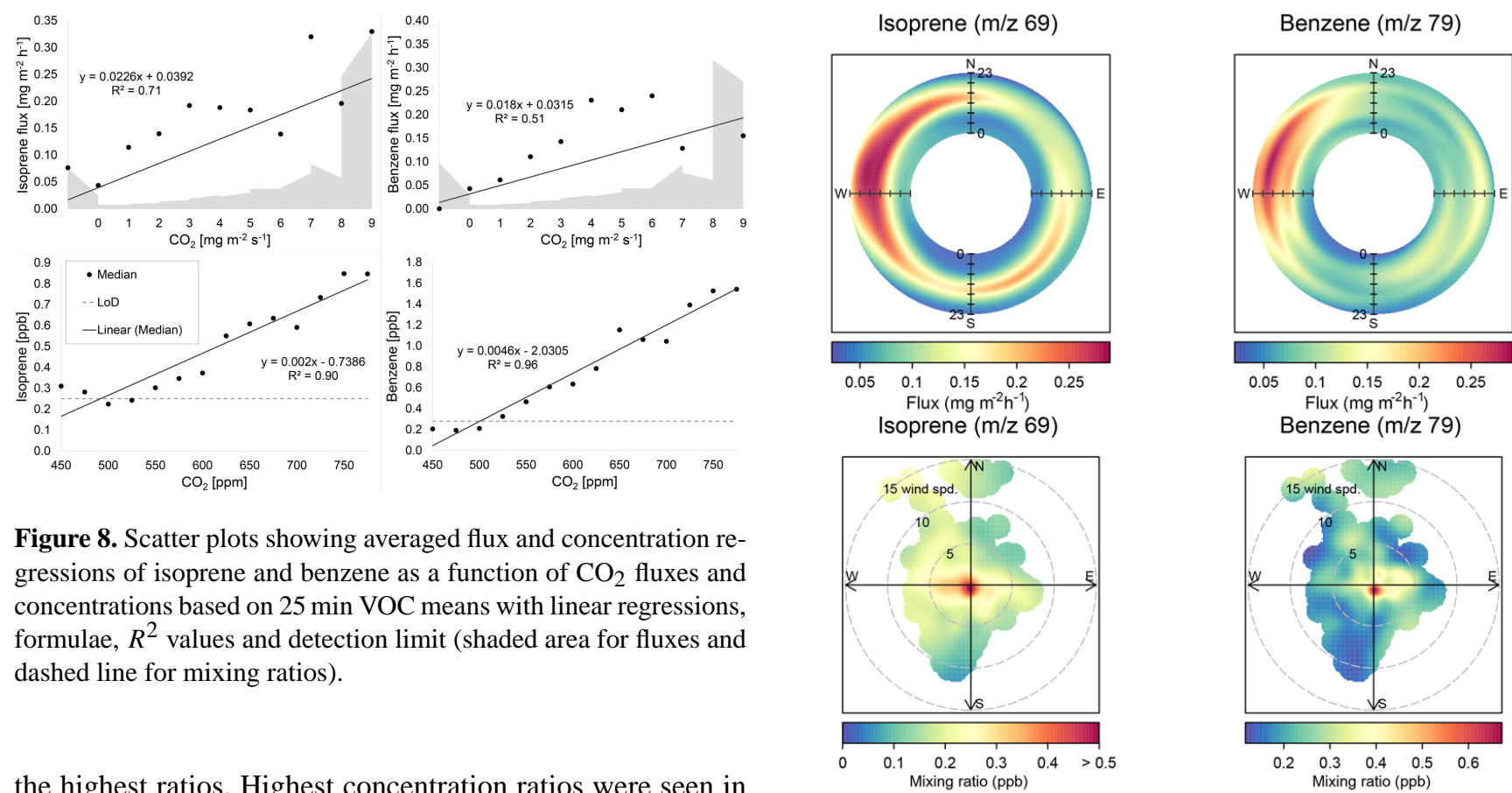

Figure 8. Scatter plots showing averaged flux and concentration regressions of isoprene and benzene as a function of $\mathrm{CO}_{2}$ fluxes and concentrations based on 25 min VOC means with linear regressions, formulae, $R^{2}$ values and detection limit (shaded area for fluxes and dashed line for mixing ratios).

the highest ratios. Highest concentration ratios were seen in August for oxygenated compounds/isoprene and December for traffic-related species.

\subsection{Wind direction and flux footprint analysis}

Polar annulus and polar plots were constructed for VOC fluxes and mixing ratios respectively and representative compounds are shown (Fig. 9). Polar plots use a generalized additive model to interpolate between wind direction and wind speed averaged data points within the OpenAir package in R (see Carslaw and Ropkins, 2012; Hastie and Tibshirani, 1990; Wood, 2006). Polar annulus plots averaged by time of day instead of wind speed show diurnal variability with wind direction. The majority of the time ( $83 \%)$, unstable and near neutral conditions prevailed $(\zeta<0.2)$, although the frequency varied between months with $87,89,82,84$ and $69 \%$ during August, September, October, November and December respectively. Wind directions with mostly unstable conditions were with $\mathrm{W}$ and $\mathrm{S}$ winds and near neutral with $\mathrm{N}$ or $\mathrm{E}$ winds. Mixing ratios were on average highest with low wind speeds (showing a negative correlation) when pollutants accumulate due to reduced mixing, indicating local emissions (Fig. 9, bottom).

Largest fluxes for all compounds were from the NW with either one daytime peak (e.g. isoprene) or two distinct rush hour peaks (e.g. benzene) (Fig. 9, top). On average, fluxes were largest from the $\mathrm{W}>\mathrm{E} \geq \mathrm{N}>\mathrm{S}(F$ statistic $=60.37$ 227.06, $p<0.001$ ) because of increased emission rates of specific compound sources. Separated by month, fluxes were largest from $\mathrm{W}>\mathrm{N}>\mathrm{E} \geq \mathrm{S}$ in August and September, whereas during October, November and December fluxes followed the pattern $\mathrm{W}>\mathrm{E} \geq \mathrm{N}>\mathrm{S}$. The flux footprint in this study was relatively small compared to that of measurements 
tions of traffic-related compound fluxes were statistically significant from the $\mathrm{W}$ (i.e. squares 4,5 , and 7 ), followed by the $\mathrm{N}$ (square 8) and $\mathrm{E}$ (squares 6 and 9) likely from the nearby heavily trafficked roads (Kingsway, Charing Cross, Strand and Blackfriars areas respectively). Biogenic compound fluxes were highest from the $\mathrm{W}$ and $\mathrm{E}$, which coincides with significant nearby green areas within the flux footprint.

Correlations of fluxes with grid square contributions in the footprint can also give information on emission source strengths within the respective grid square (Fig. 1). Generally positive correlations with fluxes across most compounds were seen from the $\mathrm{W}$ (squares 4,5 and 7), confirming that high emission rates from sources within these grid squares were driving the large fluxes. The strongest correlations of fluxes with contributions from squares 4,5 and 7 were seen during October and November $\left(R^{2}=0.40\right.$ $0.46, p<0.001$ ), especially for masses associated with biogenic sources $(m / z, 33,45,59$ and 69). Square 8 showed positive correlations for benzene and only in August for all compounds. Correlations of fluxes with contributions from squares 1, 2, 3, 6 and 9 were negative, indicating weaker emission sources in these squares or increased VOC deposition.

Highest mixing ratios with wind direction were from $\mathrm{E}>\mathrm{N} \geq \mathrm{W}>\mathrm{S}$ for traffic-related compounds, whereas oxygenated compounds/isoprene followed a similar pattern as the fluxes of $\mathrm{W} \geq \mathrm{E}>\mathrm{N} \geq \mathrm{S}$ ( $F$ statistic $=47.49-86.95$, $p<0.001)$. Easterly winds in London are often associated with synoptic conditions that bring European continental air masses to the UK, resulting in higher background concentrations. Furthermore, since the boundary layer was on average more stably stratified and mixing heights were lowest $(640 \pm 80 \mathrm{~m})$ with $\mathrm{E}$ wind conditions, it is likely that pollutant concentrations were allowed to build up, resulting in the observed higher concentrations to the $\mathrm{E}$ for the more ubiquitous compounds, whereas concentrations of compounds with biogenic contributions additionally had strong sources to the W, such as several green areas (St. James' Park, Hyde Park and Regents Park; total 331 ha).

\subsection{Comparisons with LAEI and NAEI}

The LAEI and NAEI produce yearly emission estimates over the $1 \mathrm{~km}^{2}$ OS grid for a range of pollutants and emission sources. Total VOC emission estimates are provided, but only benzene and 1,3-butadiene are estimated separately. Measured emissions were compared with annual estimated emissions for the above OS grid area selection from 2012 for benzene using the LAEI and indirectly speciated VOCs of the NAEI. Using the average flux footprint, the grid square estimates were compared with the scaled flux measurements from the equivalent area (Fig. 10).

LAEI emission estimates included contributions from major $(69 \%)$ and minor roads $(4 \%)$ as well as evaporative

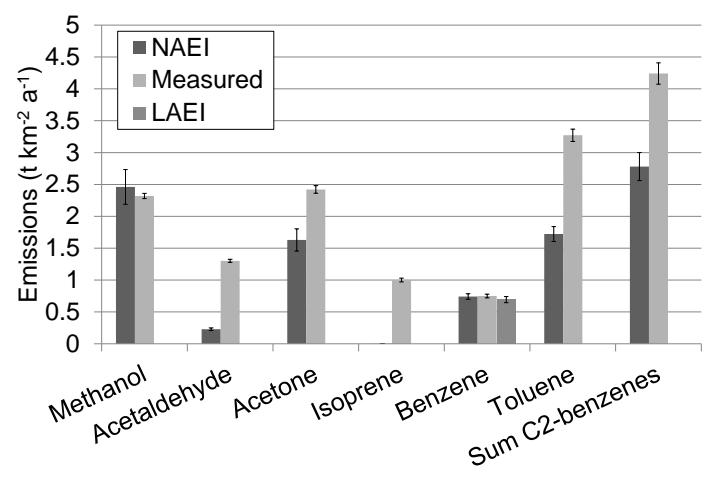

Figure 10. Bar chart showing scaled comparisons of LAEI and NAEI estimates against measured fluxes in $\mathrm{t} \mathrm{km}^{-2} \mathrm{a}^{-1}$ for speciated VOCs with error bars.

emissions (27\%) (LAEI). No data were available on cold start emissions for benzene. The calculated standard errors provided some uncertainty approximation. Measured fluxes compared well with emission estimates, although the LAEI predicted slightly smaller benzene fluxes. Comparisons of fluxes with wind directions (Sect. 3.3) agreed well with the LAEI emission estimates for the respective grid squares with highest emissions from squares $4,5,7$ and 8 (i.e. $\mathrm{W}$ and $\mathrm{N}$ directions). This comparison assumes that the benzene fluxes during the measurement period were representative of annual emissions with any significant seasonal variation in benzene emission rates captured in this 5-month period. Section 3.1.2 confirmed that there was little month-to-month variability in the benzene flux.

Using speciated VOC emission contributions (percent of total VOC emissions) for 2006 (Bush et al., 2006) and emission maps from 2012 for total non-methane VOC emissions, speciated estimates could be compared with observations (Fig. 10). The NAEI includes a wide range of emission sources divided into 11 SNAP (Selected Nomenclature for sources of Air Pollution) sectors including industrial, commercial and residential processes, transport, waste treatment, solvent use, point sources, agriculture and nature, although the latter two were unavailable for the London urban area. NAEI estimates for benzene exceed the LAEI due to the inclusion of a wider range of sources beyond trafficrelated emissions. Total $\mathrm{C}_{2}$-benzene emission estimates consisted of ethyl benzene, $(m+p)$-xylene and $o$-xylene. Benzene and methanol emissions agreed very well; however, for all the other compounds, estimated emissions were significantly lower than the measured fluxes. Uncertainties related to the measurements, such as isobaric interferences within the PTR-MS could have contributed to measurement overestimation, whereas uncertainties within the modelled emissions and the use of older speciation values may have impacted the estimates. In the case of isoprene, only minimal emissions are assumed, which do not include the biogenic sources that contributed to the measured fluxes. It is also 
likely that some of the $m / z 69$ signal could be attributed to cyclic alkenes, but Sect. 3.1.3 showed that biogenic isoprene provided a significant contribution during August and September in central London.

\section{Conclusions}

Our measurements show that vehicle emissions are the dominant source of the fluxes and concentrations of VOCs in central London, although biogenic sources and secondary atmospheric formation may make a significant contribution, particularly in summer for some compounds. There were observable spatial variations in flux rates, which result from the varying spatial distribution of emission types and strengths of emission sources, such as vegetation and traffic. Temporal variations in relative source strengths can be seen in the diurnal and seasonal profiles, reflecting the diurnality and seasonality of some of the driving factors. The measured VOC fluxes mostly originated from an area within a $1 \mathrm{~km}$ radius around the measurement site but some instances of pollution advection were seen to affect concentrations at the site. However many of the spatio-temporal differences in the observed mixing ratios were attributable to changes in emission sources and strengths combined with effects of meteorological conditions. The diurnal and seasonal dynamics of the boundary layer mixing height are significant drivers of changes in observed VOC concentrations at the site.

The biogenic component of isoprene emissions was modelled using the G95 algorithm, and the calculated base emission rate closely matched previous published values for urban areas. Even in this central urban area with a temperate climate there is a detectable biogenic component to isoprene emissions. Because of the relative importance of isoprene in atmospheric chemistry, its inclusion in photochemical pollution models is essential.

Close agreement between the flux footprint contributions and the LAEI for benzene emissions, a compound which is thought to be accurately estimated in the inventory but associated with high measurement uncertainty, gives confidence in the PTR-MS measurements. Good agreement was also seen with methanol estimated from the NAEI, but other compounds were all greatly underestimated in the emissions inventory.

This study provides further evidence for the successful implementation of VOC flux measurements in heterogeneous urban landscapes when measurement sites fulfil basic eddy covariance criteria. Further VOC flux observations are essential for the validation of "bottom-up" emission inventories, especially as the latter are widely used for regulatory and compliance purposes.

The Supplement related to this article is available online at doi:10.5194/acp-15-7777-2015-supplement.
Author contributions. E. Nemitz and B. Langford planned the measurement campaign; A. Valach made the measurements with the help of B. Langford and E. Nemitz; A. Valach processed the data and completed the analyses with the help of B. Langford. C. N. Hewitt designed the study, obtained funding and supervised the work. A. Valach prepared the manuscript with support from all the coauthors.

Acknowledgements. This work was funded by the UK Natural Environment Research Council (NERC) through the ClearfLo project (Clean Air for London; NERC grant NE/H003169/1) and the National Capability function of the Centre for Ecology \& Hydrology. Amy Valach thanks NERC for a PhD studentship. David Carslaw (King's College London) and the NOAA Air Resources Laboratory (ARL) provided the HYSPLIT back trajectories. Lisa Whalley (University of Leeds) provided the $\mathrm{OH}$ data. Sue Grimmond (University of Reading), Simone Kotthaus (University of Reading) and the urban meteorology research group at King's College London provided site access, meteorology and $\mathrm{CO}_{2}$ data. E. House, M. Shaw, W. J. Acton and B. Davison provided technical assistance.

Edited by: A. Pozzer

\section{References}

Andreae, M. O. and Merlet, P.: Emission of trace gases and aerosols from biomass burning, Global Biogeochem. Сy., 15, 955-966, doi:10.1029/2000GB001382, 2001.

Atkinson, R.: Atmospheric chemistry of VOCs and $\mathrm{NO}_{x}$, Atmos. Environ., 34, 2063-2101, doi:10.1016/S1352-2310(99)00460-4, 2000.

Bohnenstengel, S. I., Belcher, S. E., Allan, J. D., Allen, G., Bacak, A., Bannan, T. J., Barlow, J. F., Beddows, D. C. S., Bloss, W. J., Booth, A. M., Chemel, C., Coceal O., Di Marco, C. F., Faloon, K. H., Fleming, Z. L., Furger, M., Geitl, J. K., Graves, R. R., Green, D. C., Grimmond, C. S. B., Halios, C., Hamilton, J. F., Harrison, R. M., Heal, M. R., Heard, D. E., Helfter, C., Herndon, S. C., Holmes, R. E., Hopkins, J. R., Jones, A. M., Kelly, F. J., Kotthaus, S., Langford, B., Lee, J. D., Leigh, R. J., Lewis, A. C., Lidster, R. T., Lopez-Hilfiker, F. D., McQuaid, J. B., Mohr, C., Monks, P. S., Nemitz, E., Ng, N. L., Percival, C. J., Prévôt, A. S. H., Ricketts, H. M. A., Sokhi, R., Stone, D., Thornton, J. A., Tremper, A. H., Valach, A. C., Visser, S., Whalley, L. K., Williams, L. R., Xu, L., Young, D. E., and Zotter, P.: Meteorology, air quality, and health in London: The ClearfLo project, B. Am. Meteorol. Soc., 96, 779-804, doi:10.1175/BAMS-D-1200245.1, 2015.

Bush, T., Tsagatakis, I., King, K., and Passant, N.: NAEI UK Emission, Mapping Methodology, NAEI Reference: 45321001/0/AO6069/NP, AEA Technology plc, Harwell, Oxfordshire, UK, 2006.

Carslaw, D. C. and Ropkins, K.: Openair - an R package for air quality data analysis, Environ. Model. Softw., 27-28, 52-61, 2012.

City of Westminster: Trees and the Public Realm (Draft), London: City of Westminster, City Planning Delivery Unit, London, UK, 2009. 
Clarke, J. U.: Evaluation of censored data methods to allow statistical comparisons among very small samples with below detection limit observations, Environ. Sci. Technol., 32, 177-183, 1998.

Corrêa, S. M. and Arbilla, G.: Aromatic hydrocarbons emissions in diesel and biodiesel exhaust, Atmos. Environ., 40, 6821-6826, 2006.

de Gouw, J. A. and Warneke, C.: Measurements of volatile organic compounds in the Earth's atmosphere using proton-transferreaction mass spectrometry, Mass Spectrom. Rev., 26, 223-257, 2007.

de Gouw, J. A., Middlebrook, A. M., Warneke, C., Goldan P. D., Kuster, W. C., Roberts, J. M., Fehsenfeld, F. C., Worsnop, D. R., Canagaratna, M. R., Pszenny, A. A. P., Keene, W. C., Marchewka, M., Bertman, S. B., and Bates, T. S.: Budget of organic carbon in a polluted atmosphere: Results from the New England Air Quality Study in 2002, J. Geophys. Res., 110, D16305, doi:10.1029/2004JD005623, 2005.

Department for Transport: Traffic count data for the City of London, available at: http://www.dft.gov.uk/traffic-counts/area.php? region=London, last access: 05 August 2014.

Draxler, R. R. and Rolph, G. D.: HYSPLIT (HYbrid Single-Particle Lagrangian Integrated Trajectory) Model, available at: http:// www.arl.noaa.gov/HYSPLIT_info.php (last access: 13 August 2014, retrieved 12 September 2014), from NOAA ARL READY, 2008.

Foken, T. and Wichura, B.: Tools for quality assessment of surfacebased flux measurements, Agr. Forest Meteorol., 78, 83-105, doi:10.1016/0168-1923(95)02248-1, 1996.

Foken, T., Göckede, M., Mauder, M., Mahrt, L., Amiro, B., and Munger, W.: Post-field data quality control, in: Handbook of micrometeorology, edited by: Lee, X. M., Kluwer Academic Publishers, Dordrecht, the Netherlands, 181-208, 2004.

Garrat, J.: The Atmospheric Boundary Layer, Cambridge University Press, Cambridge, UK, 1992.

Geron, C. D., Guenther, A. B., and Pierce, T. E.: An improved model for estimating emissions of volatile organic compounds from forests in the eastern United States, J. Geophys. Res.Atmos., 99, 12773-12791, 1994.

Guenther, A., Hewitt, C. N., Erickson, D., Fall, R., Geron, C., Graedel, T., Harley, P., Klinger, L., Lerdau, M., McKay, W. A., Pierce, T., Scholes, B., Steinbrecher, R., Tallamra, R., Taylor, J., and Zimmerman, P.: A global model of natural volatile organic compound emissions, J. Geophys. Res., 100, 8873-8892, doi:10.1029/94JD02950, 1995.

Harley, R. A. and Cass, G. R.: Modeling the Concentrations of GasPhase Toxic Organic Air Pollutants: Direct Emissions and Atmospheric Formation, Environ. Sci. Technol., 28, 88-98, 1994.

Hastie, T. J. and Tibshirani, R.: Generalized additive models, Chapman and Hall, London, UK, 1990.

Hayward, S., Hewitt, C. N., Sartin, J. H., and Owen, S. M.: Performance characteristics and applications of a proton transfer reaction-mass spectrometer for measuring volatile organic compounds in ambient air, Environ. Sci. Technol., 36(7), 1554-60, 2002.

Heeb, N. V, Forss, A., Bach, C., Reimann, S., Herzog, A., and Ja, H. W.: A comparison of benzene, toluene and C-benzenes mixing ratios in automotive exhaust and in the suburban atmosphere during the introduction of catalytic converter technology to the Swiss Car Fleet, Atmos. Environ., 34, 3103-3116, 2000.
Helfter, C., Famulari, D., Phillips, G. J., Barlow, J. F., Wood, C. R., Grimmond, C. S. B., and Nemitz, E.: Controls of carbon dioxide concentrations and fluxes above central London, Atmos. Chem. Phys., 11, 1913-1928, doi:10.5194/acp-11-1913-2011, 2011.

Helsel, D. R. and Hirsch, R. M.: Statistical methods in water resources, Elsevier, New York, USA, 1992.

Hewitt, C. N., Hayward, S., and Tani, A.: The application of proton transfer reaction-mass spectrometry (PTR-MS) to the monitoring and analysis of volatile organic compounds in the atmosphere, J. Environ. Monitor., 5, 1-7, doi:10.1039/b204712h, 2003.

Horst, T. W.: A simple formula for attenuation of eddy fluxes measured with first-order-response scalar sensors, Bound.-Lay. Meteorol., 82, 219-233, 1997.

Kansal, A.: Sources and reactivity of NMHCs and VOCs in the atmosphere: a review, J. Hazard. Mater., 166, 17-26, doi:10.1016/j.jhazmat.2008.11.048, 2009.

Karl, T. G., Spirig, C., Rinne, J., Stroud, C., Prevost, P., Greenberg, J., Fall, R., and Guenther, A.: Virtual disjunct eddy covariance measurements of organic compound fluxes from a subalpine forest using proton transfer reaction mass spectrometry, Atmos. Chem. Phys., 2, 279-291, doi:10.5194/acp-2-279-2002, 2002.

Karl, T. G., Apel, E., Hodzic, A., Riemer, D. D., Blake, D. R., and Wiedinmyer, C.: Emissions of volatile organic compounds inferred from airborne flux measurements over a megacity, Atmos. Chem. Phys., 9, 271-285, doi:10.5194/acp-9-271-2009, 2009.

Kim, Y. M., Harrad, S., and Harrison, R. M.: Concentrations and sources of VOCs in urban domestic and public microenvironments, Environ. Sci. Technol., 35, 997-1004, 2001.

Kljun, N., Calanca, P., Rotachhi, M.W., and Schmid, H. P.: A simple parameterisation for flux footprint predictions, Bound.-Lay. Meteorol., 503-523, 2004.

Kormann, R. and Meixner, F. X.: An analytical footprint model for non-neutral stratification, Bound.-Lay. Meteorol., 99, 207-224, 2001.

Kotthaus, S. and Grimmond, C. S. B.: Identification of Micro-scale Anthropogenic $\mathrm{CO}_{2}$, heat and moisture sources - Processing eddy covariance fluxes for a dense urban environment, Atmos. Environ., 57, 301-316, doi:10.1016/j.atmosenv.2012.04.024, 2012.

Kotthaus, S. and Grimmond, C. S. B.: Energy exchange in a dense urban environment - Part I: Temporal variability of long-term observations in central London, Urban Climate, 10, 261-280, doi:10.1016/j.uclim.2013.10.002, 2014a.

Kotthaus, S. and Grimmond, C. S. B.: Energy exchange in a dense urban environment - Part II: Impact of spatial heterogeneity of the surface, Urban Climate, 10, 281-307, doi:10.1016/j.uclim.2013.10.001, 2014b.

Lamsal, L. N., Martin, R. V., Padmanabhan, A., van Donkelaar, A., Zhang, Q., Sioris, C. E., Chance, K., Kurosu, T.P., and Newchurch, M. J.: Application of satellite observations for timely updates to global anthropogenic $\mathrm{NO}_{x}$ emission inventories, Geophys. Res. Lett., 38, L05810, doi:10.1029/2010GL046476, 2011.

Langford, B., Davison, B., Nemitz, E., and Hewitt, C. N.: Mixing ratios and eddy covariance flux measurements of volatile organic compounds from an urban canopy (Manchester, UK), Atmos. Chem. Phys., 9, 1971-1987, doi:10.5194/acp-9-1971-2009, 2009. 
Langford, B., Misztal, P. K., Nemitz, E., Davison, B., Helfter, C., Pugh, T. A. M., MacKenzie, A. R., Lim, S. F., and Hewitt, C. N.: Fluxes and concentrations of volatile organic compounds from a South-East Asian tropical rainforest, Atmos. Chem. Phys., 10, 8391-8412, doi:10.5194/acp-10-8391-2010, 2010a.

Langford, B., Nemitz, E., House, E., Phillips, G. J., Famulari, D., Davison, B., Hopkins, J. R., Lewis, A. C., and Hewitt, C. N.: Fluxes and concentrations of volatile organic compounds above central London, UK, Atmos. Chem. Phys., 10, 627-645, doi:10.5194/acp-10-627-2010, 2010b.

Langford, B., Acton, W., Ammann, C., Valach, A., and Nemitz, E.: Eddy-covariance data with low signal-to-noise ratio: time-lag determination, uncertainties and limit of detection, Atmos. Meas. Tech. Discuss., 8, 2913-2955, doi:10.5194/amtd-8-2913-2015, 2015.

Lemieux, P. M., Lutes, C. C., and Santoianni, D. A.: Emissions of organic air toxics from open burning: a comprehensive review, Prog. Energ. Combust., 30, 1-32, 2004.

Lindinger, W., Hansel, A., and Jordan, A.: On-line monitoring of VOCs at pptv levels by means of PTR-MS. Medical applications, food control and environmental research, Int. J. Mass Spectrom., 173, 191-241, doi:10.1016/0015-1882(95)90197-3, 1998.

Lipari, F., Dasch, J. M., and Scruggs, W. F.: Aldehyde emissions from wood-burning fireplace, Environ. Sci. Technol., 18, 326330,1984

Met Office UK: UK Climate summaries, available at: http:// www.metoffice.gov.uk/climate/uk/summaries/2012, last access: 09 October 2013.

Moncrieff, J., Finnigan, R. C. J., and Meyers, T.: Averaging, detrending, and filtering of eddy covariance time series, in: Handbook of Micrometeorology, edited by: Lee, W. M., Kluwer Academic Publishers, Dordrecht, the Netherlands, 7-30, 2004.

Neftel, A., Spirig, C., and Ammann, C.: Application and test of a simple tool for operational footprint evaluations, Environ. Pollut., 152, 644-652, doi:10.1016/j.envpol.2007.06.062, 2008.

Nemitz, E., Hargreaves, K. J., McDonald, A. G., Dorsey, J. R., and Fowler, D.: Meteorological measurements of the urban heat budget and $\mathrm{CO}_{2}$ emissions on a city scale, Environ. Sci. Technol., 36, 3139-3146, 2002.

Park, C., Schade, G. W., and Boedeker, I.: Flux measurements of volatile organic compounds by the relaxed eddy accumulation method combined with a GC-FID system in urban Houston, Texas, Atmos. Environ., 44, 2605-2614, doi:10.1016/j.atmosenv.2010.04.016, 2010.

Park, C., Schade, G. W., and Boedeker, I.: Characteristics of the flux of isoprene and its oxidation products in an urban area, J. Geophys. Res., 116, D21303, doi:10.1029/2011JD015856, 2011.

Schade, G. W. and Goldstein, A. H.: Fluxes of oxygenated volatile organic compounds from a ponderosa pine plantation, J. Geophys. Res., 106, 3111-3123, 2001.

Singh, H. B., O'Hara, D., Herlth, D., Sachsse, W., Blake, D. R., Bradshaw, J. D., Kanakidou, M. and Crutzen, P. J.: Acetone in the atmosphere: Distribution, source, and sinks, J. Geophys. Res., 99, 1805-1819, 1994.

Spirig, C., Neftel, A., Ammann, C., Dommen, J., Grabmer, W., Thielmann, A., Schaub, A., Beauchamp, J., Wisthaler, A., and Hansel, A.: Eddy covariance flux measurements of biogenic VOCs during ECHO 2003 using proton transfer re- action mass spectrometry, Atmos. Chem. Phys., 5, 465-481, doi:10.5194/acp-5-465-2005, 2005.

Srivastava, A., Sengupta, B., and Dutta, S. A.: Source apportionment of ambient VOCs in Delhi City, Sci. Total Environ., 343, 207-220, 2005.

Stewart, I. D. and Oke, T. R.: Local Climate Zones for Urban Temperature Studies, B. Am. Meteorol. Soc., 93, 1879-1900, doi:10.1175/BAMS-D-11-00019.1, 2012.

Taipale, R., Ruuskanen, T. M., Rinne, J., Kajos, M. K., Hakola, H., Pohja, T., and Kulmala, M.: Technical Note: Quantitative long-term measurements of VOC concentrations by PTR-MS measurement, calibration, and volume mixing ratio calculation methods, Atmos. Chem. Phys., 8, 6681-6698, doi:10.5194/acp8-6681-2008, 2008.

Valach, A. C., Langford, B., Nemitz, E., MacKenzie, A. R., and Hewitt, C. N.: Concentrations of selected volatile organic compounds at kerbside and background sites in central London, Atmos. Environ., 95, 456-467, doi:10.1016/j.atmosenv.2014.06.052, 2014.

Velasco, E., Lamb, B., Pressley, S., Allwine, E., Westberg, H., and Jobson, B. T.: Flux measurements of volatile organic compounds from an urban landscape, Geophys. Res. Lett., 32, 2-5, doi:10.1029/2005GL023356, 2005.

Velasco, E., Lamb, B., Westberg, H., Allwine, E., Sosa, G., ArriagaColina, J. L., Jobson, B. T., Alexander, M. L., Prazeller, P., Knighton, W. B., Rogers, T. M., Grutter, M., Herndon, S. C., Kolb, C. E., Zavala, M., de Foy, B., Volkamer, R., Molina, L. T., and Molina, M. J.: Distribution, magnitudes, reactivities, ratios and diurnal patterns of volatile organic compounds in the Valley of Mexico during the MCMA 2002 \& 2003 field campaigns, Atmos. Chem. Phys., 7, 329-353, doi:10.5194/acp-7-329-2007, 2007.

Velasco, E., Pressley, S., Grivicke, R., Allwine, E., Coons, T., Foster, W., Jobson, B. T., Westberg, H., Ramos, R., Hernández, F., Molina, L. T., and Lamb, B.: Eddy covariance flux measurements of pollutant gases in urban Mexico City, Atmos. Chem. Phys., 9, 7325-7342, doi:10.5194/acp-9-7325-2009, 2009.

Vilà-Guerau de Arellano, J., van den Dries, K., and Pino, D.: On inferring isoprene emission surface flux from atmospheric boundary layer concentration measurements, Atmos. Chem. Phys., 9, 3629-3640, doi:10.5194/acp-9-3629-2009, 2009.

Warneke, C., van der Veen, C., de Gouw, J. A., and Kok, A.: Measurements of benzene and toluene in ambient air using protontransfer-reaction mass spectrometry: calibration, humidity dependence, and field intercomparison, Int. J. Mass Spectrom., 207 167-182, 2001.

Warneke, C., de Gouw, J. A., Kuster, W. C., Goldan, P. D., and Fall, R.: Validation of atmospheric VOC measurements by proton-transfer-reaction mass spectrometry using a gaschromatographic pre-separation method, Environ. Sci. Technol., 37, 2494-501, 2003.

Warneke, C., McKeen, S. A., de Gouw, J. A., Goldan, P. D., Kuster, W. C., Holloway, J. S., Williams, E.J., Lerner, B.M., Parrish, D.D., Trainer, M., Fehsenfeld, C., Kato, S., Atlas, E.L., Baker, A., and Blake, D. R.: Determination of urban volatile organic compound emission ratios and comparison with an emissions database, J. Geophys. Res., 112, D10S47, doi:10.1029/2006JD007930, 2007. 
Wood, S.: Generalized Additive Models: An introduction with R. Chapman and Hall/CRC, CRC Press, Taylor \& Francis Group LLC, Boca Raton, FL, USA, 2006.

Yuan, B., Warneke, C., Shao, M., and de Gouw, J. A.: Interpretation of volatile organic compound measurements by proton-transfer-reaction mass spectrometry over the deepwater horizon oil spill, Int. J. Mass Spectrom., 358, 43-48, doi:10.1016/j.ijms.2013.11.006, 2014.
Zavala, M., Herndon, S. C., Slott, R. S., Dunlea, E. J., Marr, L. C., Shorter, J. H., Zahniser, M., Knighton, W. B., Rogers, T. M., Kolb, C. E., Molina, L. T., and Molina, M. J.: Characterization of on-road vehicle emissions in the Mexico City Metropolitan Area using a mobile laboratory in chase and fleet average measurement modes during the MCMA-2003 field campaign, Atmos. Chem. Phys., 6, 5129-5142, doi:10.5194/acp-6-5129-2006, 2006. 